\title{
Effectiveness of resilient
}

wheels in reducing noise and vibrations

\section{B. Suarez, J. A. Chover, P. Rodriguez and F.J. Gonzalez}

This study focuses on the effectiveness of resilient wheels in reducing railway noise and vibrations, and compares the effectiveness of three types of wheels. The finite elements method has been used to characterise the vibratory behaviour of these wheels. The model has been excited with a realistic spectrum of vertical track irregularities, and a spectral analysis has been carried out. Results have been post-processed in order to estimate the sound power emitted. These calculations have been used to assess the effectiveness of the resilient wheel designs in reducing noise emitted to the environment and in propagating structural vibrations. 


\title{
Effectiveness of resilient wheels in reducing noise and vibrations
}

\author{
B. Suarez ${ }^{1 *}$, J. A. Chover ${ }^{1}$, P. Rodriguez ${ }^{1}$ and F.J. Gonzalez ${ }^{2}$ \\ ${ }^{1}$ Railway Technologies Research Centre (CITEF), Universidad Politécnica de Madrid (UPM), Madrid, Spain \\ ${ }^{2}$ Metro de Madrid S.A., Madrid, Spain \\ * Corresponding author: CITEF, C/ José Gutiérrez Abascal n², ES-28006 Madrid, Spain, email: \\ citef.bsuarez@etsii.upm.es
}

\begin{abstract}
This study focuses on the effectiveness of resilient wheels in reducing railway noise and vibrations, and compares the effectiveness of three types of wheels. The finite elements method has been used to characterise the vibratory behaviour of these wheels. The model has been excited with a realistic spectrum of vertical track irregularities, and a spectral analysis has been carried out. Results have been postprocessed in order to estimate the sound power emitted. These calculations have been used to assess the effectiveness of the resilient wheel designs in reducing noise emitted to the environment and in propagating structural vibrations.
\end{abstract}

Keywords: Resilient wheel, noise and vibrations, rolling noise, wheel-squeal, sound power, finite elements, tram, tram-train

\section{Introduction}

The study presented in this paper extends the results found in a previous work $[1,2]$ carried out by the Railway Technologies Research Centre (CITEF), in cooperation with Metro de Madrid. The aim is to assess the degree to which resilient wheels are effective in reducing noise and vibrations. For this purpose, two different resilient wheel designs have been compared with a third, more conventional design, corresponding to a monobloc wheel.

Among the different techniques that can be used to simulate the generation of rolling noise [3], the finite element method was chosen to perform this study. Quarter car models have been generated, in which the wheelset has been considered as an elastic body. In these models, the displacements caused by the vertical track irregularities, whose effects are intended to be reduced by the use of resilient wheels, have been directly applied on the wheel-rail contact patch.

Since this is a comparative study, it has not been considered necessary to determine the actual value of the sound pressure at different points of the environment. Instead, it has been considered sufficient to assess the effectiveness of each wheel design in reducing the level of noise and vibrations at the source of emission. To this end, a spectral analysis has been carried out to analyse the vibratory response of each type of wheel to realistic track excitations. Prior to the spectral analysis, which constitutes the core of this study, a harmonic analysis was carried out in the $0-3000 \mathrm{~Hz}$ frequency range, preceded by a modal analysis. Subsequently, on the basis of the results obtained from the spectral analysis, the sound power emitted by the three types of wheels was also compared.

The paper is structured in the following parts: the first part, consisting of sections 2 and 3 , deals with various theoretical concepts relating to railway noise and vibrations and to resilient wheels; section 4 describes the calculation methodology used; section 5 provides a detailed description of the wheels analysed and the finite element models used to characterise them; section 6 presents the comparative results showing the effectiveness of the resilient wheels from three different perspectives: the transmission of vibrations to the vehicle body, the transmission of vibrations to the track and the emission of noise to the surrounding air, finally, section 7 presents the conclusions of the study. 


\subsection{Sources of noise and vibrations}

Railway operations generate vibrations that are transmitted through the ground to nearby buildings. These vibrations can lead both to clearly appreciable vibrations $(4-80 \mathrm{~Hz})$ and to low-frequency rumbling noise (30-250 $\mathrm{Hz}$ ). Vibrations are also transmitted to the vehicle itself, which affects passenger comfort.

Aerodynamic noise, the noise generated in engines and the noise produced by wheel-rail contact are also transmitted inside the carbody. The sound can be transmitted through the air and through the structure itself, with structure-borne transmission dominating at low frequencies and air-borne transmission dominating at high frequencies.

Although the noise associated with aerodynamic fluctuations is the main source of noise in high-speed operations, the dominant sources of noise at speeds of below $300 \mathrm{~km} / \mathrm{h}$ have a mechanical origin, making the air around a structure vibrate, thereby transmitting the sound. The most important mechanical source is related to the wheel-rail contact. The following types of noise and vibrations associated with this source can be identified:

- Rolling noise

- Impact noise

- Squeal noise

- Ground-borne vibration and noise

The main characteristics of each type of mechanical source are described below. The interested reader can find a detailed description of this subject in [4].

\subsubsection{Rolling noise}

Vertical irregularities on wheel and rail surfaces excite both elements through their wheel-rail contact area, causing vibrations that produce a type of noise called rolling noise. When the wavelengths of the irregularities are short in comparison to the length of the contact area, their effect is attenuated, which is known as a contact filter. According to [5], the extent to which the wheel and the rail move in response to irregularities depends on their respective mechanical receptances in the vertical direction. At low frequencies, vibrations from sleepers are usually the most important source, whereas at medium frequencies (between 400 and $1600 \mathrm{~Hz}$ ) and high frequencies (above $1.6 \mathrm{kHz}$ ) the predominant sources are the rails and the wheels, respectively. With respect to the wheel, web radiation, related to axial vibration, is usually greater than tread radiation.

One particular case of rolling noise is impact noise, which is related to wheel and rail discontinuities such as rail joints, free movements at switches and crossings, dipped welds and wheel flats. These discontinuities cause strong interaction forces in the wheel-rail contact area, resulting in the vibration of both elements that produce this type of noise.

Different solutions are available for reducing rolling noise [4]: controlling the roughness of the wheel surface by installing disk brakes instead of brake blocks; controlling rail corrugation by grinding; separating the web from the tread; installing devices that increase wheel or rail damping; using soft pads that insulate sleepers from rail vibrations; using absorbent materials in the upper part of the slab track to reduce sound reflections; installing embedded rails for street running trains; or using local shielding measures such as enclosures around the bogie or acoustic barriers along the track.

Apart from the above-mentioned measures for reducing rolling noise, impact noise can also be reduced by eliminating its cause [4]: installing wheel-slide protection equipment to prevent the formation of wheel flats; replacing jointed track with continuous welded rail; levelling the welds, or installing swing nose frogs on switches.

\subsubsection{Squeal noise}

Squeal noise is caused by resonance phenomena in the wheel, associated with the appearance of unsteady friction forces in wheel-rail contact, which originate on sharp curves. Wheelset misalignment occurs on sharp curves, giving rise to creep forces in the wheel-rail contact. The behaviour caused by the presence of these creepages is similar to a negative damping, which causes the instability of the mode shapes, making the wheels prone to squeal. 
According to [4], two types of squeal noise can be distinguished depending on the excitation mechanism. The first, caused by the stick-slip excitation associated with lateral wheel slip, is usually generated on the inner leading wheel, which undergoes considerable lateral creepage. The second type, associated with flange-rail contact, is generated on the outer leading wheel.

Due to the nature of the squeal noise, this type of noise can never be eliminated, but it could be reduced [4] by using lubricants or friction modifiers that reduce the difference between static and dynamic friction coefficients, though their effectiveness is not validated today. Wheel damping is also effective.

\section{$2.2 \quad$ Noise and vibration propagation paths}

Figure 1 shows the possible paths of propagation of the noise and vibrations caused by wheel-rail interaction. The following paragraphs describe each of them in more detail.

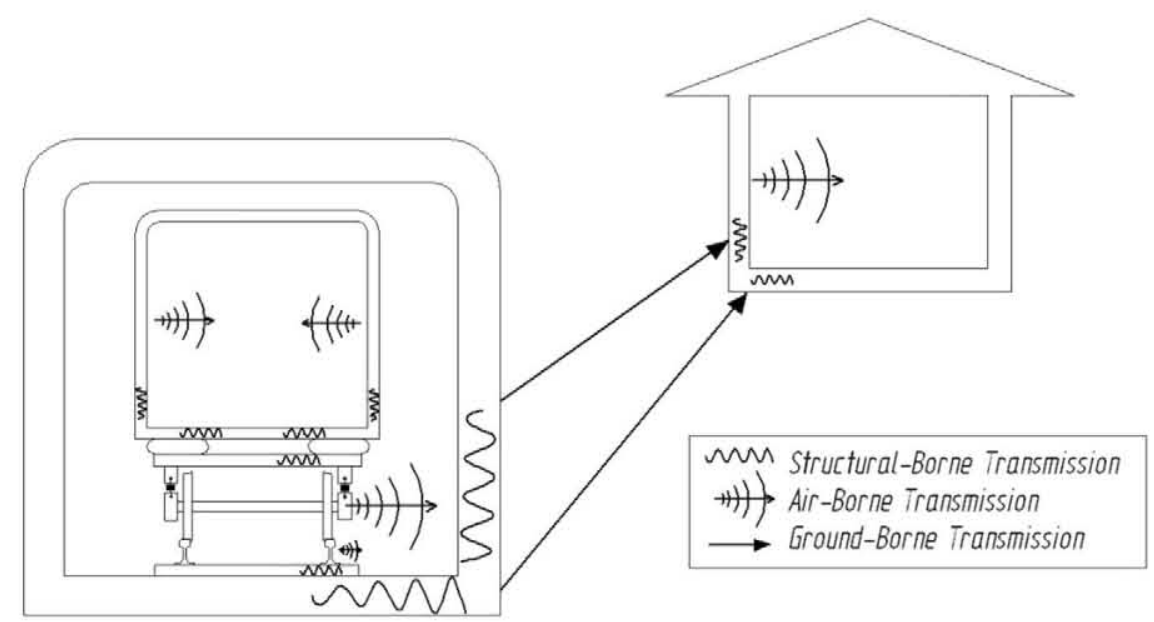

Figure 1. Noise and vibration propagation.

\subsubsection{Air-borne noise transmission}

Vibrations from the wheels, the rail and the sleepers produce noise, the magnitude of which can be assessed by means of the sound power emitted by the source, or through the sound pressure measured at a certain distance from the source.

If the sound pressure is measured outside the vehicle, at a point situated a few metres away from the rail, the wheel is usually found to be the biggest contributor in the high-frequency range; at medium frequencies the rail is the dominant element, and at low frequencies the sleepers predominate. As the running speed increases, the sound spectrum shifts toward higher frequencies, which gives more importance to wheel- related emissions.

Inside vehicles, air-borne noise is partly due to the acoustic excitation of carbody elements such as the floor, walls, doors, windows and roof, which vibrate as a result of the acoustic excitation from the outside, and which in turn cause the air inside the vehicle to vibrate.

\subsubsection{Structural-borne transmission}

Besides being transmitted through the air, noise can also be transmitted to the vehicle interior through its structure. This noise mainly comes from the vibration originated in the wheel-rail contact area, which is transmitted by suspension elements. It can also be produced by vibrations caused by the train's diesel engines.

\subsubsection{Ground-borne transmission}

Wheel and rail irregularities, together with the mobile loads transmitted by the wheelsets along the track, cause track vibrations. These vibrations excite the adjacent ground, creating vibration waves that propagate through the various soil and rock strata to the foundations of nearby buildings, and from there to the rest of the building structure. Building structure vibrations can produce feelable movements of building floors, the rattling of windows, shaking of items on shelves or hanging on walls, and rumbling noise [6].

According to Thompson [4], three different effects of ground-borne transmission can be identified. 
- When running at low speeds, vehicles with a large unsprung mass (freight trains or electric multiple units) can cause large-amplitude vibrations in the track that propagate through the ground. This type of vibration often has significant low frequency components (below $10 \mathrm{~Hz}$ ) that can interact with building frequencies. The vibration is perceived in the buildings as a whole body vibration, causing discomfort and even sleep disorders.

- High-speed trains can exceed the wave propagation speed in the ground, a phenomenon that is comparable to supersonic planes breaking the sound barrier. The vibrations generated are transmitted great distances from the track. However, this phenomenon occurs only in some locations of some countries where the ground stiffness is very low.

- In the case of trains running through tunnels, the vibration is transmitted to the buildings situated above. This vibration has a higher frequency content than the vibration caused by lines situated on the surface. Although the air-borne noise cannot be heard directly, vibrations at the lowest level of the audible frequency range $(30-200 \mathrm{~Hz})$ can excite building floors and walls, which radiate noise directly into the rooms. These vibrations can be reduced by using resilient elements in the vertical track support.

Although the human perception threshold is approximately $65 \mathrm{VdB}$, human response to vibration is not usually significant unless the vibration exceeds $70 \mathrm{VdB}$ [6]. Though generalities cannot be given in terms of $\mathrm{VdB}$, as the sources and the propagation are very different from one place to another, as an example, this level can be found around $15 \mathrm{~m}$ away from a rapid transit or light rail transit line. In unfavourable conditions, caused by deteriorated tracks or by wheel flats, geological conditions favouring the propagation of vibrations or vehicles with very rigid suspensions, the level of vibration can reach $80 \mathrm{VdB}$ at a distance of $15 \mathrm{~m}$ from a rapid transit line, and up to $85 \mathrm{VdB}$ in the case of commuter lines, on which the locomotive generates a higher level of vibrations. When these vibration levels are reached in a residential area, the degree of discomfort experienced by the occupants is very high.

Vibration levels inside a building depend on the vibration energy generated (source), the energy transmitted to the building's foundations (path), the connections between the foundation and the floor, and the propagation of the vibration in the building (receiver). According to [6], factors related to the vibration source are the vehicle's suspension, the type of wheels and their state of maintenance, the roughness of the rail, the stiffness of the track, the running speed and the depth of the source; factors related to the vibration path are the type of soil, the presence of rock strata, soil layering, water table depth and frost depth; finally, factors related to the receiver are the type of foundation, the building mass and its acoustic absorption.

In accordance with this, reduction measures can be applied at the source, along the path or in the receiving building, although the most effective measures are those which are applied directly at the source. According to [7], reduction at the source can be achieved by minimizing the unsprung mass, with a soft primary suspension and with wheel grinding; reduction along the transmission path can be achieved by increasing the distance between the transit line and the receiver by using continuous welded rail, grinding the rail, using a rail with greater mass, installing resilient rail fasteners, ballast mats or floating sleepers and slabs. Once the vibration has been transmitted to the ground, reduction measures are more difficult to apply, although vibration insulation techniques can also be applied to the building's foundations in special circumstances.

\section{General concepts relating to resilient wheels}

As has been seen, the transmission of noise and vibrations can cause a considerable nuisance in the vicinity of a transit line, and constitutes a serious environmental problem associated with urban and suburban railways. Once the vibration is transmitted to the ground, it is more difficult to apply palliative measures, and therefore corrective measures are usually applied to the track (resilient rail fasteners, ballast mats, floating sleepers...) or to the vehicle (soft primary suspensions, small unsprung masses, etc.).

Among the constructive measures used to reduce this effect, resilient wheels play an important role in metropolitan railways and tramways. They were initially designed for light transit systems, to reduce dynamic stress levels in unsprung masses, rolling noise emitted on straight track and wheel squeal noise on sharp curves $[5,8,9,10]$. Since then they have been used intensively for years, with apparently satisfactory results [11].

Although there are various types of resilient wheels [10, 12-16], they all share the same basic principle, which consists in inserting a slightly compressed resilient layer between the tread and the hub, both of which are made of steel. This resilient layer, which usually takes the form of a V-shaped ring, acts as a third suspension stage, helping to suppress the rolling noise and the vibrations transmitted to the vehicle body and the track, while at the same time reducing impact on the track. With respect to rolling noise, the use of resilient wheels has three 
positive effects. Firstly, separating the web from the tread by inserting a resilient layer leads to a reduction in web vibration and radiation; secondly, the damping effect of rubber, which is stronger than that of steel, reduces vibration levels for the whole wheel; and finally, the reduction of mechanical impedance allows the wheel to act as a vibration absorber with respect to the rail, which reduces the vibration and radiation of both the wheel and the track [5].

Resilient wheels also ensure an elastic transmission of traction and braking forces, and help reduce wheel and rail wear, thereby increasing the service life of the wheel. All these characteristics make resilient wheels especially suitable for use in urban and suburban mass transport systems when compared with conventional monobloc wheels.

In spite of their advantages, traditional resilient wheels also have certain disadvantages. On the one hand, due to the characteristics of the rubber material, resiliency in the axial direction, where the rubber is exposed to shear, is high, which is a drawback [12]. Resilient wheels also have more eigenmodes that are susceptible to be excited during running [5]. In addition, rubber undergoes greater thermal expansion than steel and exerts a stronger influence on the stress state of the wheel rim when it is subjected to a normal load and the vehicle is running at a high speed [17]. Another problem with this type of wheel is the high loss factor of rubber material [17]. In an attempt to avoid these problems, new resilient wheel designs have been developed in recent years [12, $18,16]$.

Although resilient wheels are rarely used for running on main lines, when the first noise problems arose in the initial versions of the ICE trains, due to polygonalization problems in the wheels, the original monobloc wheels were replaced by resilient wheels inspired by light transit systems $[18,13,19]$. This measure reduced the noise problem, but increased the stress state in the tread, which eventually caused the complete disintegration of one of these wheels in the summer of 1998 [20,21,22]. This was the starting point of a tragic sequence of unfortunate events that led to the accident in Eschede (Germany). This accident dealt a severe blow to the incorporation of resilient wheels in high-speed trains. As a result, few research papers on the effectiveness of this type of wheel have been published, in spite of the fact that thousands of them are still in operation on urban transit lines without having caused any noteworthy accidents. Despite the lack of publications on this subject, it is worth highlighting the research work published by P. Bouvet [5] and H. Claus [19].

\section{$4 \quad$ Calculation methodology}

\subsection{Spectral analysis}

The vibratory response of the vehicle to a realistic track excitation has been calculated, taking into account the actual amplitude of irregularities for each excitation frequency. This has been done by using a power spectral density function (PSD) corresponding to a railway track, on which components with long wave lengths have higher amplitudes than those with short wave lengths. Short wave defects (from $20 \mathrm{~cm}$ to $3 \mathrm{~m}$ ) are related to the shape of the rail and the welded joints, whereas the medium waves (from 3 to $25 \mathrm{~m}$ ) and the long waves (more than $25 \mathrm{~m}$ ) are associated with geometric defects in the ballast layer and the subgrade [23].

The PSD function published by the ERRI B176 committee [24] has been used to define vertical irregularities. This function represents a track with a low-level vertical irregularity, and responds to the formula:

$$
S_{z}^{* *}=A_{z} \frac{\Omega^{2}{ }_{C}}{\Omega^{2}+\Omega^{2}{ }_{R} j \Omega^{2}+\Omega^{2}{ }_{C}}
$$

where $\Omega_{C}=0.8246 \mathrm{rad} / \mathrm{m}, \Omega_{R}=0.0206 \mathrm{rad} / \mathrm{m}$ and $A_{z}=4.032 \cdot 10^{-7} \mathrm{~m} \cdot \mathrm{rad}, \Omega$ being the spatial frequency.

As the vehicle runs along the track, the wheels pass over the irregularities at a certain speed, whereby the spatial irregularities $\mathrm{z}(\mathrm{s})$ are converted into time excitations $\mathrm{z}(\mathrm{t})$ applied on the wheels. The PSD of the timerelated irregularities, $\mathrm{S}_{z}(\omega)$, and the PSD of the spatial irregularities, $\mathrm{S}_{\mathrm{z}}(\Omega)$, are related to the vehicle's speed, V, by means of the formula:

$$
S_{z}^{*}(\omega)=\frac{1}{V^{2}} S_{z}^{*}(\Omega)
$$

On railway tracks, the maximum wave length is normally about $100 \mathrm{~m}$, which, for the speed of $70 \mathrm{~km} / \mathrm{h}$ used in this study, corresponds to a minimum frequency of $0.2 \mathrm{~Hz}$. To the contrary, a track excitation of over $3000 \mathrm{~Hz}$ is considered insignificant, even if the audible spectrum reaches higher values. So in order to analyse the effectiveness of the system in terms of reducing noise emission, its response has been calculated for frequencies 
of up to $3000 \mathrm{~Hz}$. For a running speed of $70 \mathrm{~km} / \mathrm{h}$, frequencies of up to $3000 \mathrm{~Hz}$ correspond to wave lengths of more than $6.5 \mathrm{~mm}$.

The vibratory response of any point in the system analysed can be related to excitation through a transfer function, $\mathrm{H}(\omega)$, which is different for each point considered. Once the transfer function $\mathrm{H}(\omega)$ for a specific point of the vehicle is known, its PSD can be related to that on the track according to the following formula:

$$
S_{d}(\omega)=\mid H \Phi^{z} \cdot S_{z}^{*}(\omega)
$$

$\mathrm{S}^{*}$ being the PSD function of the vertical excitation of the track and $\mathrm{S}_{\mathrm{d}}$ being the PSD of the displacement of a generic point of the vehicle.

Although the PSD function obtained directly in this work represents the displacement of a generic point of the wheel, in studies of noise and vibrations it is more useful to know the PSD function of the speed, as will be seen later on. In order tofind the relationship between both functions, it can be used the transfer function, $H(\omega)$, which relates the displacement, $\mathrm{D}(\omega)$, of a point on the wheel to the vertical excitation of the track, $Z(\omega)$ :

$$
H(\omega)=\frac{D(\omega)}{Z^{*}(\omega)} \Rightarrow D(\omega)=H(\omega) \cdot Z^{*}(\omega)
$$

Multiplying both terms by $\omega$ :

$$
\omega \cdot D(\omega)=\omega \cdot H(\omega) \cdot Z^{*}(\omega) \quad \text { (eq. 5) }
$$

The left hand term of this formula is the Fourier transform of the first derivative of the displacement of the wheel point, $d(t)$, or, in other words, the Fourier transform of the speed of this point, $v_{n}(t)$. Taking this into account, and with $\mathrm{G}$ being the product of $\omega$ multiplied by $\mathrm{H}$, the above formula can be rewritten as:

$$
V_{n}(\omega)=G(\omega) \cdot Z^{*}(\omega) \quad \text { (eq. 6) }
$$

On the basis of this formula, it is possible to apply one of the properties of the spectral density functions [25], which allows the PSD functions of $\mathrm{v}_{\mathrm{n}}(\mathrm{t})$ and $\mathrm{d}(\mathrm{t})$ to be related through the module of the transfer function $\mathrm{G}(\omega)$ by means of the formula:

$$
S_{v}(\omega)=|G(\omega)|^{2} \cdot S_{z}^{*}(\omega) \quad \text { (eq. 7) }
$$

And, remembering that $\mathrm{G}$ is the product of $\omega$ multiplied by $\mathrm{H}$, the resultant formula is:

$$
S_{v}(\omega)=\omega^{2} \cdot|H(\omega)|^{2} \cdot S_{z}^{*}(\omega)
$$

Using the latter formula, it is possible to calculate the PSD function of the vibration speed of a generic point on the wheel on the basis of the PSD function of the track irregularities, which is known, and the transfer function that relates displacement of this point to vertical track excitation, which will be obtained from the finite element models.

Considering these formulas, it is clear that the necessary transfer functions must be obtained prior to this spectral analysis by means of a harmonic analysis. At this stage of the analysis, a sinusoidal vertical displacement of constant amplitude and variable frequency between 0 and $3000 \mathrm{~Hz}$ is applied at the wheel-rail contact point. Once the transfer functions have been determined for the points of interest, the previous formula can be applied in order to obtain the vibratory response of these points, using the track excitation, which is known.

\subsection{Assessment of sound power generated by the wheel}

In a piece of research work presented by Efthimeros et al. [26], the outer lateral surface of the wheel is broken down into a series of concentric rings, in which all the points vibrate in the same way, and the sound power generated by the wheel is calculated as the sum of the sound power generated by each ring.

A similar methodology to the one described above has been adopted for this study. It would therefore be very useful to have an analytical formula to calculate the sound power emitted by an annular plate vibrating in a direction perpendicular to its axis. There are several published studies that formulate the mathematical equations characterising the sound radiation of annular plates or disks [27-33], all the resultant formulas being quite complex.

Given that this study only aims to compare the effectiveness of the different wheels under consideration in qualitative terms, it has been considered appropriate to find a more easily applicable approximate method, as 
opposed to using complex analytical formulations. At this point, the concept of a structure's radiation efficiency comes into play. As its name suggests, it is a measure of the efficiency with which sound is radiated, and it can be defined as the quotient between the quantity of acoustic energy radiated in a fluid and the total kinetic energy of the structure. Radiation efficiency, $\sigma$, can be expressed as $[33,4]$ :

$$
\sigma=\frac{W}{\rho \cdot c \cdot\left\langle v_{n}^{2}\right\rangle \cdot A} \quad \text { (eq. 9) }
$$

where the product $\rho \cdot c$ represents the acoustic impedance of the air, $\rho$ being its density and $c$ the speed of sound; $\mathrm{W}$ is the sound power radiated by the structure; $\mathrm{A}$ is the surface area of the source, and $\mathrm{v}_{\mathrm{n}}$ is the normal speed of the surface. The brackets indicate the average with respect to both time and space, so that the term in brackets can be considered to be the mean square value of the vibration speed. Furthermore, bearing in mind that, by virtue of Parseval's theorem [34], the mean square value of a function is obtained by integrating its power spectral density, the term in brackets can be expressed as:

$$
\left\langle v_{n}^{2}(t)\right\rangle=\int_{-\infty}^{\infty} S_{v}(f) \cdot d f \quad \text { (eq. 10) }
$$

$S_{v}(f)$ being the power spectral density of $v_{n}(t)$.

So, in accordance with the above, the wheel's radiation efficiency can be defined as a function of the power spectral density of the normal component of the speed of the points on its surface:

$$
\sigma=\frac{W}{\rho \cdot c \cdot A \cdot \int_{-\infty}^{\infty} S_{v}(f) \cdot d f}
$$

Although this formula seems more complex than the previous one, it is worth remembering that the function $\mathrm{S}_{\mathrm{v}}(\omega)$ can be obtained in the spectral analysis, and that it will simply have to be integrated into the whole range of frequencies under consideration.

According to Thompson [4], radiation efficiency is usually around 1 for high frequencies, and less than 1 for low frequencies, for which the size of the sources is small in comparison with the wave length. In the specific case of railway vehicle wheels, the geometric parameters of the wheels lead to a radiation efficiency of around 1 [35]. According to this, and bearing in mind that the aim here is just to find an approximate solution that will allow the different wheels under analysis to be compared to each other, if radiation efficiency, $\sigma$, is assumed to be equal to 1 , then on the basis of the previous formula the corresponding sound power of the wheel can be estimated as:

$$
W=\rho \cdot c \cdot A \cdot \int_{-\infty}^{\infty} S_{v}(f) \cdot d f \quad \text { (eq. 12) }
$$

Considering, as already mentioned, that the lateral surface of the wheel is broken down into $\mathrm{N}$ rings (Figure 2) to which the previous formula can be applied, the formula for the $j$-th ring is:

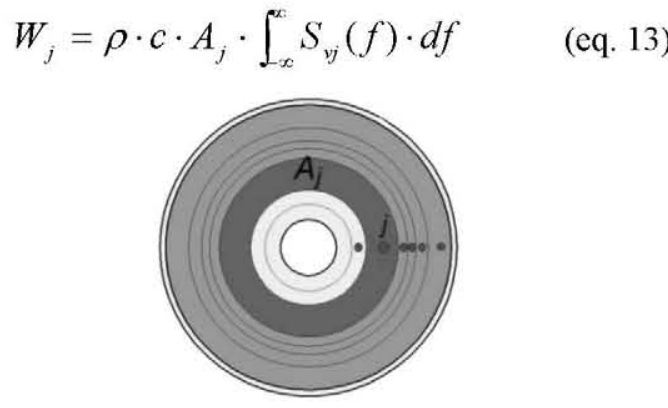

Figure 2. Division of the wheel's lateral surface into concentric rings for the sound power calculation

Finally, by adding together the contribution of each ring, the sound power corresponding to the complete wheel, $\mathrm{W}_{\mathrm{T}}$, will be:

$$
W_{T}=\rho \cdot c \cdot \sum_{j=1}^{N} \mathbf{L}_{j} \cdot \int_{-\infty}^{\infty} S_{v j}(f) \cdot d f^{-}
$$

Conceptually, this formula is similar to the empirical formula indicated in [26], which was provided by a wheel manufacturer. 
As has already been stated, two different types of resilient wheels have been analysed in this study, one with rubber blocks, and the other one with a V-shaped rubber ring. What both designs have in common is that they have three clearly differentiated parts: the hub and the tread, both metallic, and a resilient layer between the other two parts. The differences between the two resilient wheel designs lie mainly in the configuration of the resilient layer and in the fastening system used to attach the rubber to the rest of the wheel.

The main characteristics of these wheels, as well as the finite element models developed to model them with the ANSYS commercial program are described below.

\subsection{Monobloc wheel}

\subsubsection{Description of the wheel}

Figure 3 shows the monobloc wheel used for the study.
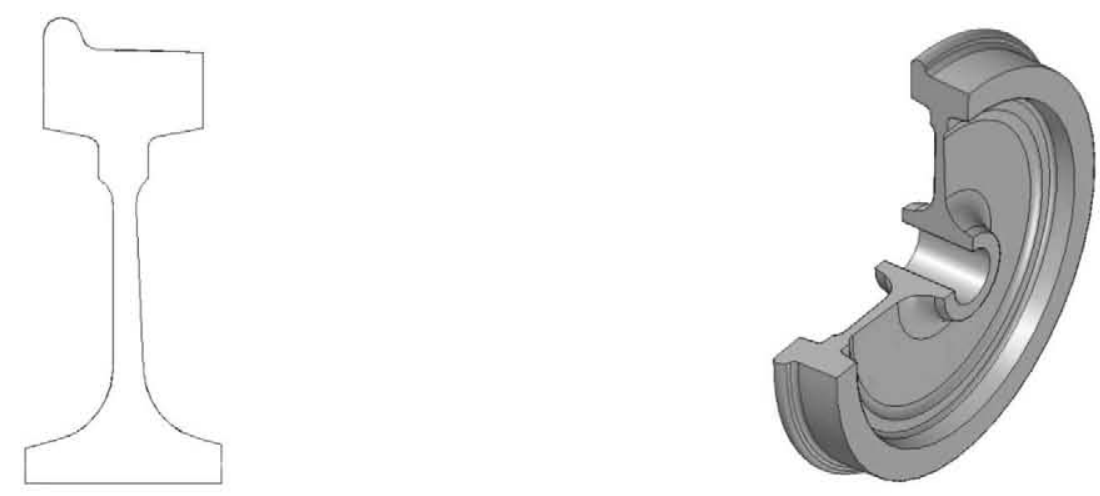

Figure 3. Cross section and 3D view of the monobloc wheel

\subsubsection{Mesh generation}

To facilitate mesh generation, the geometry of the wheel has been simplified, just replacing with sharp angles those fillets smaller than the elements used to mesh the cross section of the wheel. Figure 4 shows the final model generated for the wheelset with monobloc wheels.
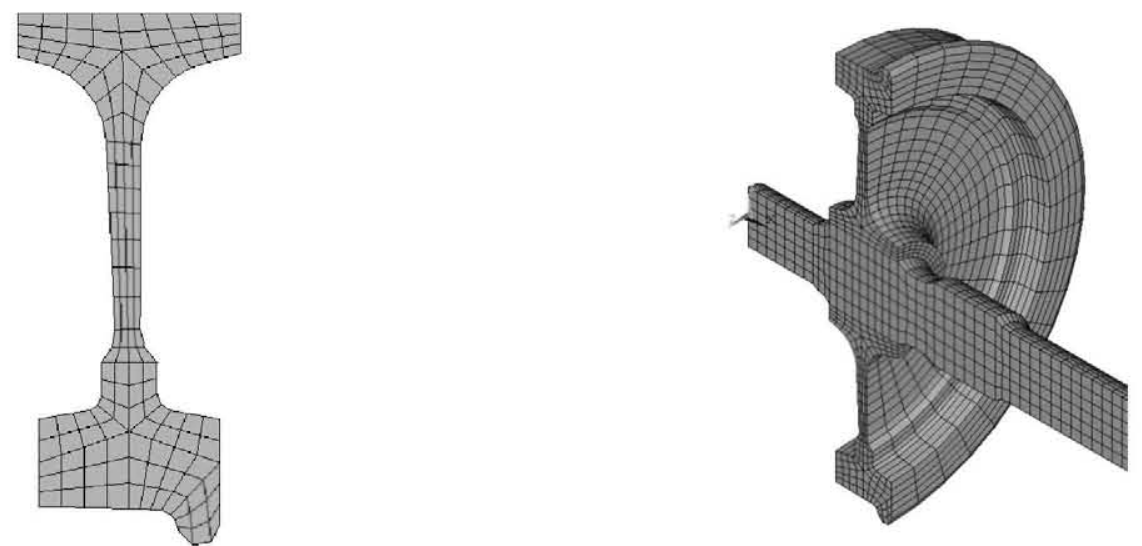

Figure 4. Cross section of the monobloc (left), and cross section mesh (right) 


\subsection{Resilient wheel with rubber blocks}

\subsubsection{Description of the wheel}

In this type of resilient wheel, the hub and the tread are separated by 24 circumferentially arranged rubber blocks, which are inserted between the hub and the tread [36]. The free space between the hub and the tread is smaller than the natural size of the blocks, which are therefore compressed during the assembly process.
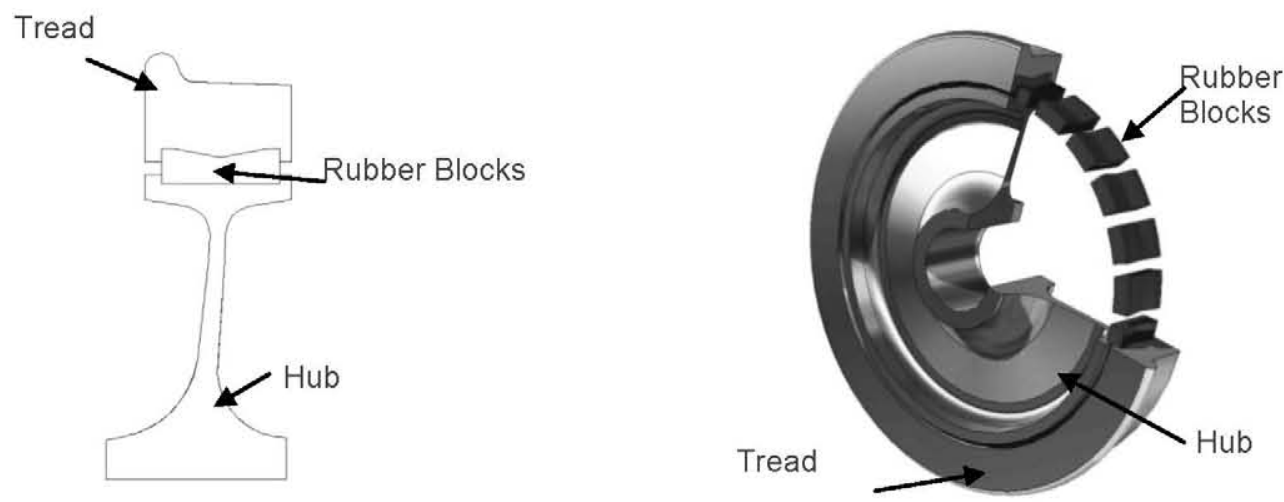

Figure 5. Cross section and $3 D$ view of the resilient wheel with rubber blocks

The rubber blocks have a V-shaped groove in the contact area with the tread (see Figure 5), whereas in the contact area with the hub they are completely flat. This geometry increases the rubber-tread contact surface area and eliminates the possibility of slipping between both surfaces. This groove also ensures that the blocks fit perfectly, thus preventing possible side-slips. Another important effect, related to the compression of the blocks, is an increase in the radial stiffness of the rubber, thereby modifying the dynamic behaviour of the wheel.

The sides of the rubber blocks, in their initial configuration, before being assembled, are not straight but concave (Figure 6). So, when the blocks are compressed during mounting, the sides are flattened to assure the design geometry.
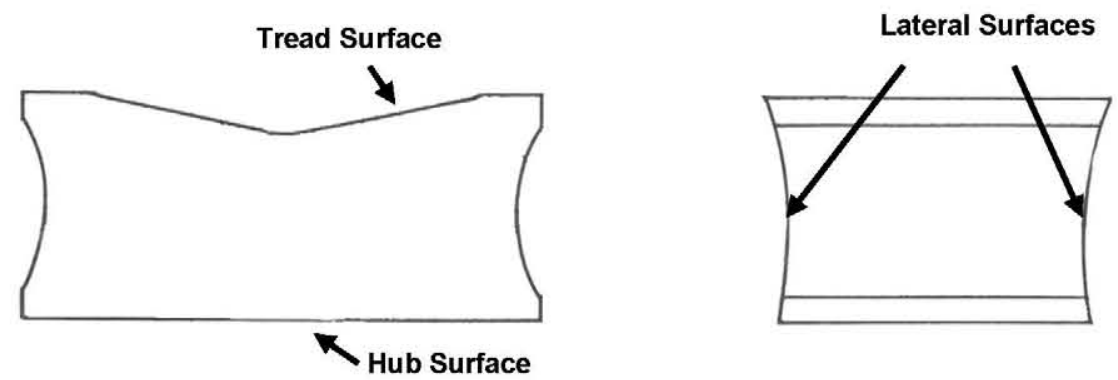

Figure 6.Rubber blocks: front (left) and side view (right) of the rubber block.

[37] analyses a wheel of similar geometry, in which the resilient characteristics of the rubber material have been varied

\subsubsection{Mesh generation}

In order to model this type of resilient wheel using finite elements, a number of simplifications were made, respecting the main characteristics at all times. The geometric shape of the blocks was also simplified, making the sides of the blocks flat instead of concave, which greatly simplifies the meshing operation.

Having defined the geometry, the cross section was meshed in first place. To ensure a regular mesh, the cross section of the wheel was previously divided into four-sided areas (Figure 7, left). Once the cross section mesh is defined (Figure 7, centre), it is revolved to generate the three-dimensional model (Figure 7, right). As for the rest of the modelled wheels, the type of element used in this operation was the SOLID45. 

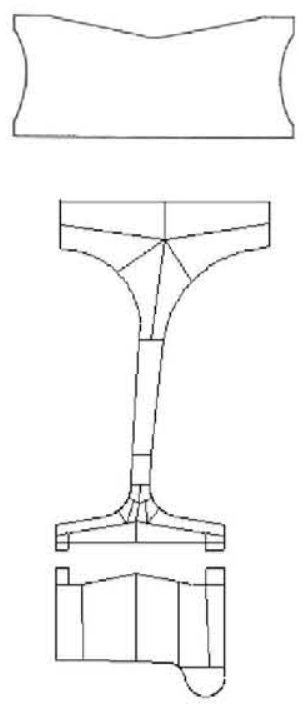
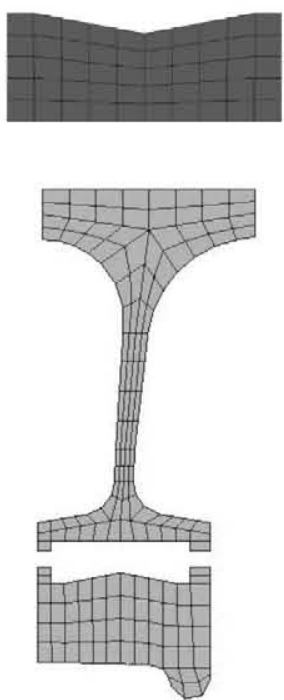

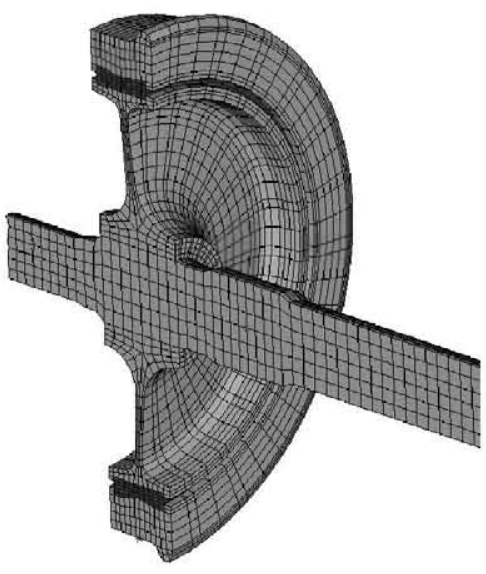

Figure 7. Cross section of the wheel divided into 4-sided areas (left), cross section mesh (centre) and 3D mesh (right)

When characterising the materials, it was assumed that the rubber only undergoes minor deformations, and that it therefore has a linear behaviour. As a result, the type of element used to characterise the rubber in ANSYS is also the SOLID45. Apart from its greater simplicity, the choice of this type of element, with linear characteristics, was also based on the type of analysis to be carried out, given that in ANSYS the spectral and frequency response analyses are based on a preliminary modal analysis which, by definition, can only be linear. For this reason, the use of non-linear elements, such as the hyperelastic elements generally used to model rubbers, was ruled out.

Table 1 shows the mechanical properties defined to characterise the rubber.

\begin{tabular}{|c|c|c|c|}
\hline Material & Young Modulus [Pa] & Poisson Modulus & Density [Kg/m3] \\
\hline Rubber & $20.4 \mathrm{e} 6$ & 0.40 & 1,100 \\
\hline
\end{tabular}

Table 1. Mechanical properties of the rubber blocks

The following section explains the procedure used to characterise the rubber assembly compression in the finite element model. This initial compression causes assembly stresses that have a direct influence on the stiffness of the rubber and, therefore, on the dynamic behaviour of the resilient wheel.

\subsubsection{Rubber pre-compression modelling}

Compressing the rubber blocks has two effects: firstly, it prevents slipping between the blocks and the steel, since there is sufficient contact pressure continuously; secondly, it modifies the stiffness of the rubber by generating a permanent stress state. Due to this second effect, the dynamic response of the wheel is modified; therefore it is important to consider this feature in the models.

In order to tackle the problem of the change in stiffness due to a stress state, a static analysis was carried out prior to the spectral analysis. During this phase of the analysis, the rubber is compressed to obtain the stress state reached after mounting the rubber.

The pre-compression process was carried out in the following way:

- The starting point is a model with the initial geometry of the rubber blocks before being compressed. Initially, only the inner surface of each block is attached to the hub, so that the blocks overlap with the tread (Figure 8, left.). Although the nodes on the underside of the block are attached to the hub, they can slide circumferentially to allow the block to expand in this direction when it is compressed in the radial direction, partly conserving its volume in this way. To the contrary, the nodes on the block's lateral surfaces that are in contact with the hub are only allowed to move in the radial direction.

- Furthermore, a radial displacement constraint of around $11 \mathrm{~mm}$ is imposed on the nodes on the upper surface of the blocks, thereby forcing the block to compress radially until it adopts the final 
mounting configuration. All wheel hub movements are also constrained, as well as the radial displacement of all points on the outermost surface of the tread.

- The next part of the process consists of a static analysis, which provides the new stress state. As can be seen (Figure 8 , right), in the static equilibrium position the rubber blocks expand in the circumferential direction to compensate the height reduction undergone.

- After the static analysis, the resultant stresses are saved, so they can be taken into account in the subsequent dynamic analysis. The position of the nodes is updated, and the common nodes between the upper surface of the blocks and the inner surface of the tread are joined together. The nodes on the lateral face of the block that are in contact with those on the hub and those on the tread are also joined to the wheel (Figure 8, right). With respect to the tread, all its degrees of freedom are permitted again. It is worth pointing out that when generating the mesh it is necessary to bear in mind the final positions that the nodes will have after the static analysis, so that the surface nodes that are in contact occupy the same final position, and can be joined together.
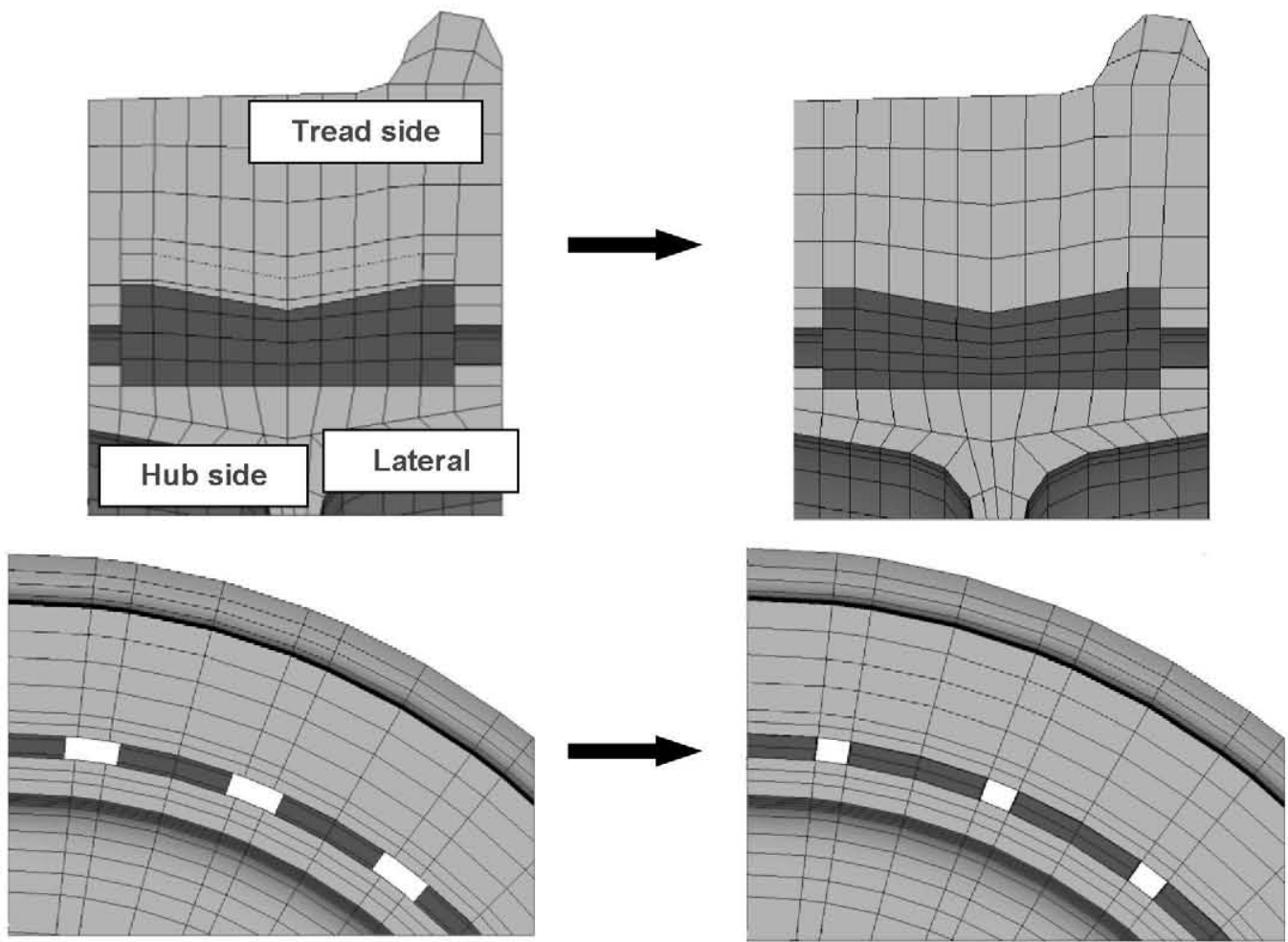

Figure 8. Pre-compression of the rubber. Initial states (left) and final states (right)

\subsection{Resilient wheel with V-ring}

\subsubsection{Description of the wheel}

This wheel is characterised by having an elastic ring with a V-shaped cross section between the hub and the tread. Figure 9 shows a simplified diagram with each part of the wheel. 

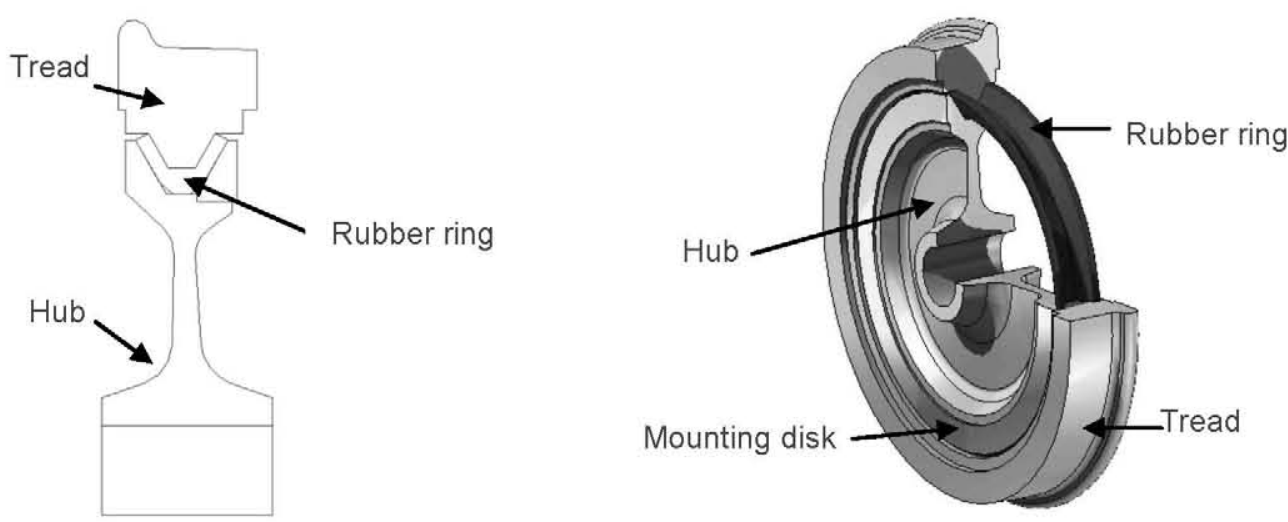

Figure 9. Cross section and $3 D$ view of the resilient wheel with V-ring

The rubber ring consists of a single annular part that does not completely fill the space between the hub and the tread. The cross section of the rubber has a V shape (Figure 10), in which the sides form an angle of $60^{\circ}$ with the wheel's axis. Given this configuration, the parts of the rubber which work in normal operation are its sides, which are exposed to both compression and shear. Only in exceptional situations, when the wheel is subjected to severe stresses, does the central part of the rubber work as well, exposed to compression. This design, therefore, provides a gradual increase in stiffness. Furthermore, the fact that the sides incline at an angle of $60^{\circ}$ means that the stiffness is greater in the radial direction than in the axial direction.

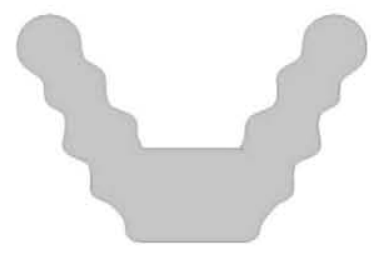

Figure 10. Cross section of rubber ring in the resilient wheel with V-ring.

During the assembly process, the mounting disk (Figure 9) slightly compresses the rubber ring, thereby ensuring that there is always a contact pressure that guarantees the rubber ring's adherence, both to the tread and to the hub.

The mounting disk is fastened to the wheel hub with a set of uniformly distributed screws. These screws pass through the rubber ring, which has ready-made holes in it for this purpose. This design provides two advantages: firstly, it ensures a compact wheel, and secondly, it prevents possible slips between the rubber and the wheel hub.

The hub, the tread and the mounting disk have some annular grooves on the surfaces that are in contact with the rubber (Figure 10). This geometry increases the area of contact between the rubber and the metal part of the wheel, thereby reducing the risk of slipping between both surfaces.

The surface of the tread that is in contact with the centre of the rubber ring is not parallel to the wheel's axis, but at a slight angle to it. This serves two purposes: to facilitate assembly and to compensate the lateral forces that are produced when the wheel flange comes into contact with the rail.

\subsubsection{Mesh generation}

The process used to model this type of wheel is similar to the one used for the resilient wheel with rubber blocks, although in this case the geometry of the resilient wheel is somewhat more complicated than in the previous case. The main geometric simplifications in this case are described below:

- The grooves in the contact area between the rubber and the steel have been removed. Their function of preventing slipping between the rubber and the rest of the wheel has been characterised by constraining movement between the nodes on contact surfaces. This fulfils the same purpose as in reality, which is to reduce the risk of slipping between the rubber and the steel.

- The geometry of the hub surface that is in contact with the rubber has been simplified by eliminating the angle of inclination with respect to the wheel's axis. This does not affect the results, because, as will be seen later on, the excitations are applied to the model in the radial direction and not in the axial one. 
- The screws have been eliminated from the mounting disk fastening system. This fastening has been characterised by constraining movements between the nodes of the hub and the mounting disk, which come into contact after assembly.

As before, and once the final geometry has been determined, the cross section of the wheel was divided into four-sided areas to ensure a regular mesh. Subsequently, this cross section was meshed (Figure 11, left) and then revolved to generate the three-dimensional model (Figure 11, right).
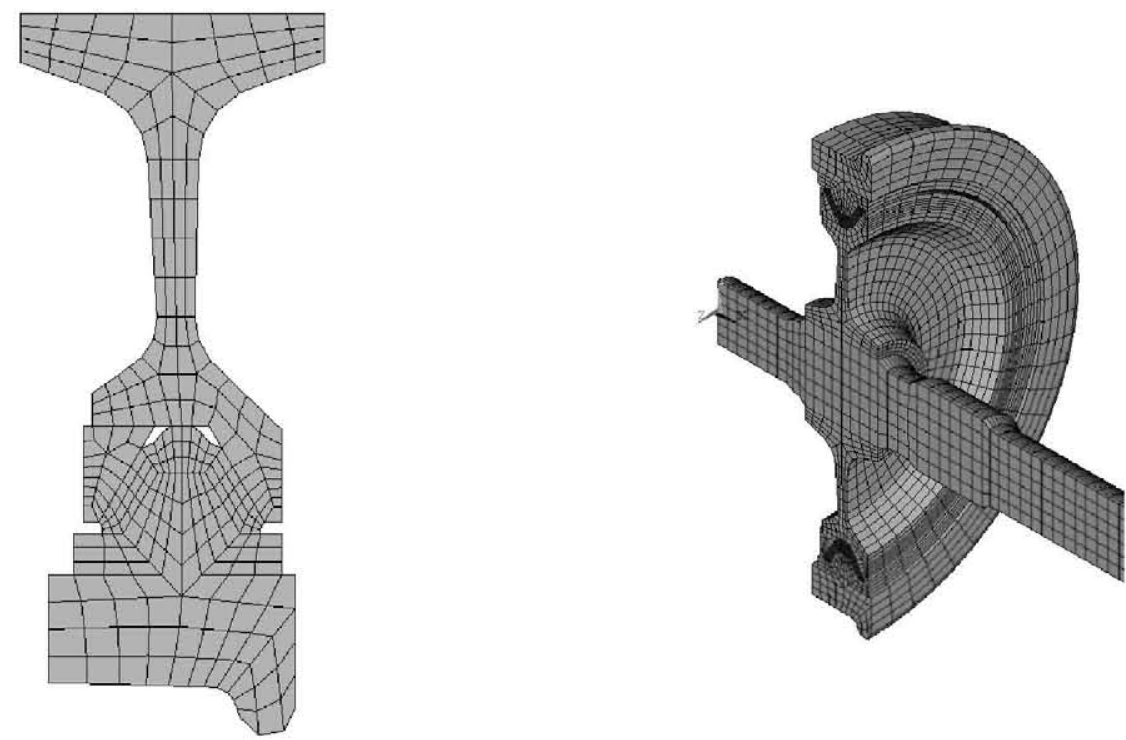

Figure 11. Cross section mesh (left) and 3D model (right)

As in the previous case, the rubber is assumed to have a linear behaviour. Table 2 indicates the characteristics of the rubber used in this case.

\begin{tabular}{|c|c|c|c|}
\hline Material & Young Modulus [Pa] & Poisson Modulus & Density [Kg/m3] \\
\hline Rubber & $20.4 \mathrm{e} 6$ & 0.48 & 1,100 \\
\hline
\end{tabular}

Table 2. Mechanical properties of the rubber ring

\subsubsection{Rubber pre-compression modelling}

On this occasion it is also necessary to bear in mind the initial compression of the rubber, which was carried out in the following way:

- The starting point is a model with the geometry of the uncompressed rubber and with the mounting disk displaced axially towards the wheel exterior over a distance $d_{a}$ with respect to its mounting position, so that it remains in contact with the outer side of the undeformed rubber (Figure 12, left). At this stage of the analysis, the rubber is completely attached to the tread, whereas the hub and the disk are only attached to the sides of the rubber (the fastening points are represented in the diagram by green crosses), so that the central area remains free. With regard to the boundary conditions applied, all wheel hub movements are constrained, and a displacement $d_{a}$ is applied to the mounting disk over the outer surface, so that it remains mounted in its final position.

- Using this configuration, a static calculation is made to determine the rubber ring mounting stresses.

- After the static analysis, the resultant stresses are saved, so they can be taken into account in the subsequent dynamic analysis. The position of the nodes is also updated, and the mounting disk is attached to the hub, as are the surfaces of the rubber and the hub that have not yet been joined together (Figure 12, right). It should be pointed out that it is necessary to take note of the final positions of the nodes when generating the mesh, so as to be able to join the corresponding nodes together later on. 

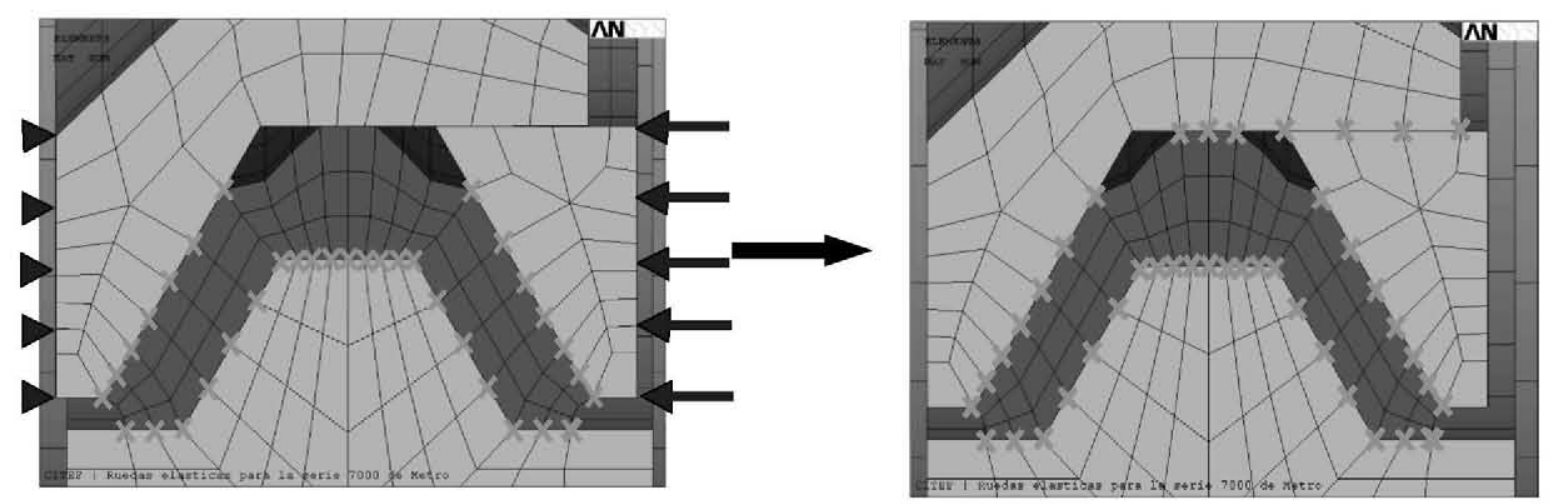

Figure 12. Pre-compression of the rubber. Initial state (left) and final state (right)

The distance $d_{a}$ over which the disk is displaced before being mounted, has been calculated by bearing in mind the value of the interference $i$ between the steel and each of the four sides of the rubber (Figure 13). Although the actual value of $i$ is $1.9 \mathrm{~mm}$, bearing in mind that the grooves on the steel surface in contact with the rubber have not been considered in the model, if this value were to be introduced in the model, the stresses generated would be greater than the actual ones. In order to avoid this effect, a value of approximately half the real value has been used, $0.9 \mathrm{~mm}$.

The displacement of the mounting disk is related to the interference (Figure 13) through the formula:

$$
d_{a}=4 \cdot d=4 \cdot \frac{i}{\operatorname{sen} \alpha}
$$

$\alpha$ being the angle of the side of the rubber ring, which takes a value of $60^{\circ}$.

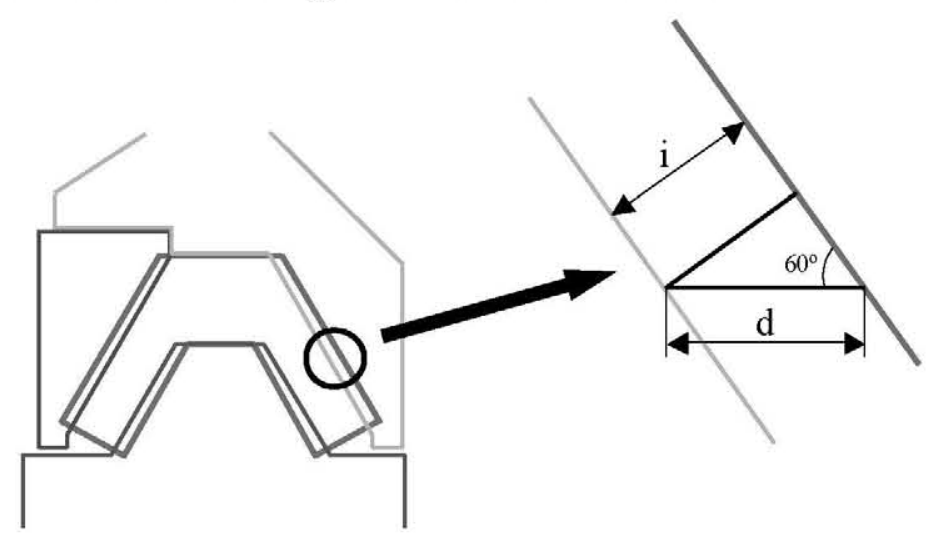

Figure 13. Mounting disk displacement calculation on the basis of interference between rubber and steel

\subsection{Characteristics common to all the models}

\subsubsection{Introduction of unsprung masses}

To compare the three types of wheels, a vehicle model that is common to all of them has been constructed. A quarter car model has been considered, so that only a single wheelset is modelled.

Only the wheelset has been discretized by means of finite elements, given that the study focuses on the dynamic response of this body. Both the bogie and the carbody have been considered to be rigid bodies (MASS21 element in ANSYS).

The brake disk has been modelled as a lumped mass, because although it is not necessary to know how it becomes deformed, its dynamic effect on the wheelset does have to be taken into account.

Suspensions have been modelled with spring elements (COMBIN14 en ANSYS), whereby each suspension is a single element.

Table 3 shows the properties of the different vehicle components. 


\begin{tabular}{|c|c|c|}
\hline Body & Mass [Kg] & Roll Moment of Inertia [Kg· $\left.{ }^{2}\right]$ \\
\hline Carbody & 38800 & 59000 \\
\hline Bogie & 2200 & 2115 \\
\hline Brake Disk & 150 & 44.6 \\
\hline Suspension & Stiffness [N/m] & Damping [N/ms] \\
\hline Primary & 5150000 & 5100 \\
\hline Secondary & 645500 & - \\
\hline
\end{tabular}

Table 3. Values for vehicle model component properties

As regards the boundary conditions used, and bearing in mind that the main external cause of vibration is that produced by the track's vertical irregularities, the most important vibrations in the wheel will be those whose movements are contained in a plane perpendicular to the track's axis. The same will occur for the rest of the vehicle. Mode shapes that are not contained in this plane (torsion, bending on a horizontal plane, etc.) can be disregarded therefore, since they will not be excited. As a result, only half of the wheelset can be considered, taking advantage of its geometric and boundary condition symmetry.

Given that only the wheelset deformations on the vertical plane perpendicular to the track are considered, it is logical to assume that both the bogie and the carbody can only move on this plane. If both bodies are modelled as rigid solids, it is therefore only necessary to consider two degrees of freedom: vertical displacement and rocking rotation.

For the purpose of modelling track excitation in the wheel-rail contact area, vertical constraints in the contact patch have been defined. The displacement condition is that imposed by the track excitation itself.

Figure 14 shows the complete quarter car model, with the resilient wheelset.

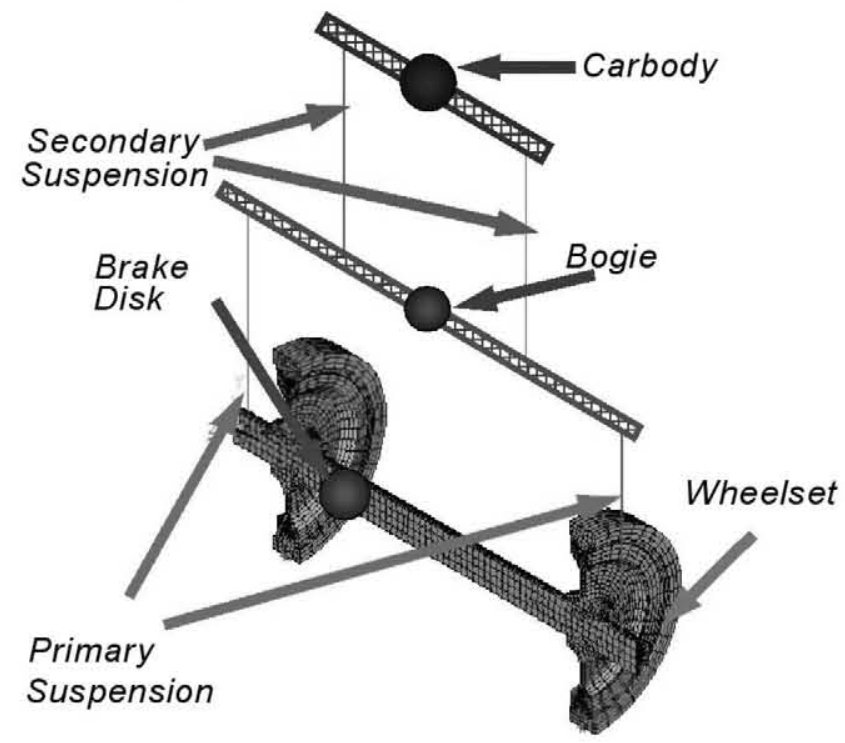

Figure 14. Quarter vehicle model with resilient wheels and rubber blocks

\subsubsection{Connection with suspension elements}

In principle, in the wheelset-primary suspension connection, force is transmitted through a single node, which would cause unrealistic local deformations. In order to avoid this problem, the node placed at the end of the spring is connected to a dummy node, which distributes the suspension force over a set of 'slave' nodes placed on the wheelset surface on which the axle-box bearing would be mounted (see Figure 15). 


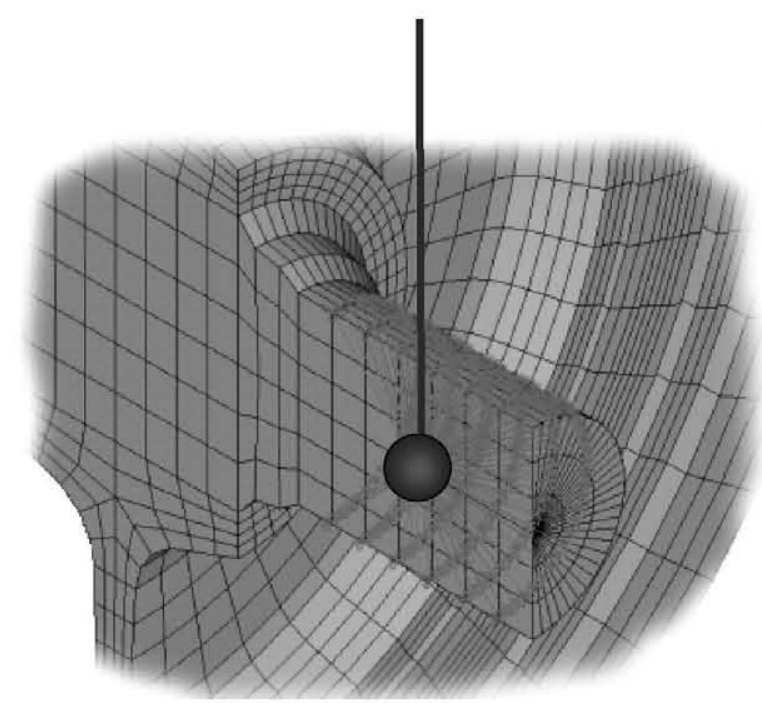

Figure 15. Distribution of the primary suspension's reaction force over an area of the wheelset

\subsubsection{Definition of excitations}

The excitation transmitted to the wheel as a consequence of the track irregularities must be applied in the wheel-rail contact area, in the form of a displacement constraint with a certain law. To be precise, it is simulated by introducing a sinusoidal displacement in the wheel-rail contact area.

Assuming that the size of the contact area is around $3 \mathrm{~cm}^{2}$ [23], a constraint could be applied to a single node, which would cause unrealistic local deformations. Another option would be to apply the constraint to the whole contact area, which because of its small dimensions would require a very fine mesh in that part of the model. In order to avoid these drawbacks, an intermediate solution has been chosen, which involves stiffening the contact area and applying the displacement constraint to an additional node rigidly attached to this area (Figure 16), so that all the nodes in the stiffened area undergo the same displacement.

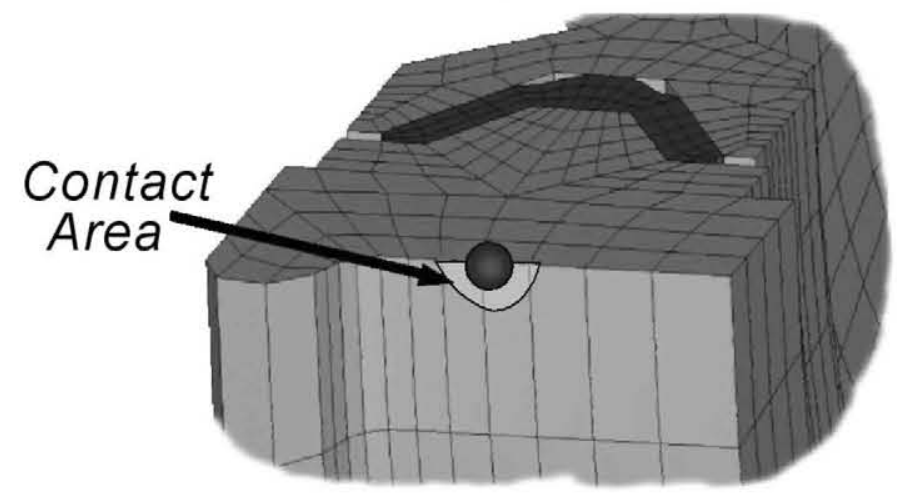

Figure 16. Stiffening of the wheel-rail contact area

Two different cases of excitation have been considered (Figure 17): in the first case, the same excitation is applied to both wheels of the wheelset (case A), whereas in the second case, excitations are phase shifted $180^{\circ}$. What is most likely to happen is that the vertical track irregularities will be phase shifted by an angle of between 0 and $180^{\circ}$, which is why it is useful to study extreme cases, in phase and counterphase. 

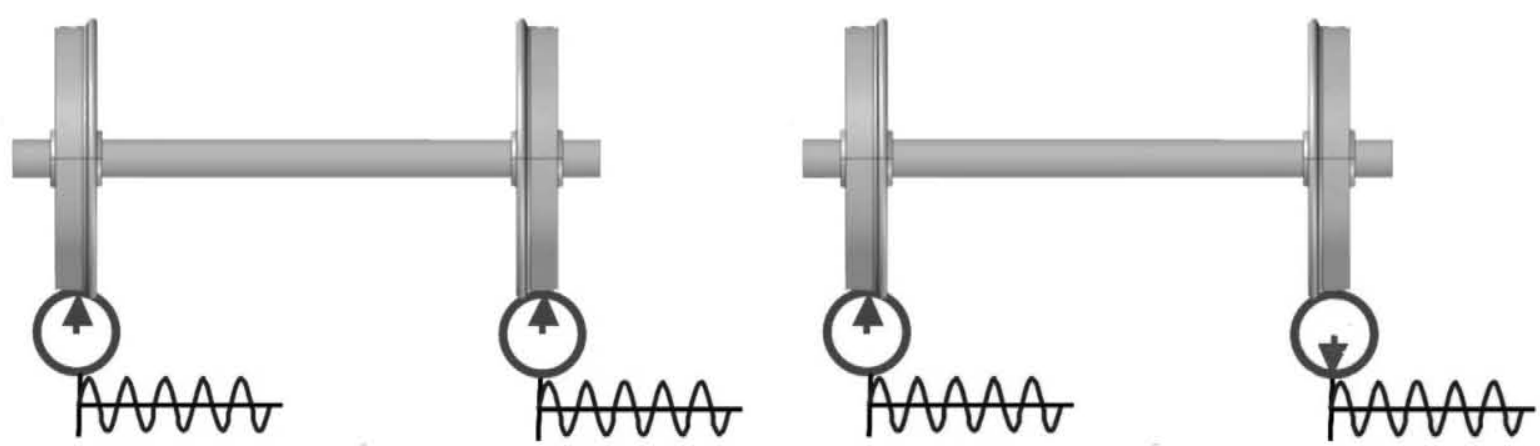

Figure 17. Case A: excitation in phase (left) and case B: excitation in counterphase (right)

\section{Results of the analysis}

This section presents the results of the spectral analysis. In this analysis, the PSD functions of the speed at the most significant points of the model have been obtained. The aim is to compare the effectiveness of the resilient wheels analysed in terms of noise and vibration reduction from three different perspectives:

- Transmission of structural vibrations to the carbody

- Transmission of structural vibrations to the track

- Emission of wheel noise to the surrounding air

For this reason, in accordance with these perspectives, the points for which the PSD function has been found are, respectively:

- The centre of gravity of the carbody and the bogie, and the points of connection between the wheelset and the primary suspension, in order to analyse vibrations transmitted to the rest of the vehicle.

- Wheel-rail contact reaction forces and the related vertical movement of the track, in order to obtain vibrations transmitted to the track.

- Various points on the outer lateral surface of the wheel, in order to assess the sound radiation emitted to the exterior.

Before presenting the results of the spectral analysis, some results of the previous modal analysis have been included to provide a clearer understanding of the systems analysed.

\subsection{Modal analysis}

The aim of the modal analysis is to determine how each eigenmode occurs, as well as the frequency at which it occurs. Table 4 shows the first 16 frequencies obtained for vehicle models with monobloc wheels and with both types of resilient wheels. 


\begin{tabular}{|l|c|c|c|}
\hline \multirow{2}{*}{ Description of the eigenmode } & \multicolumn{3}{|c|}{ Frequency [Hz] } \\
\cline { 2 - 4 } & Monobloc wheel & \multicolumn{2}{|c|}{ Resilient wheels } \\
\cline { 3 - 4 } & & with rubber blocks & with V-ring \\
\hline Carbody roll & 0.94 & 0.93 & 0.94 \\
\hline Carbody vertical displacement & 1.25 & 1.25 & 1.25 \\
\hline Bogie roll & 15.28 & 13.51 & 14.82 \\
\hline Bogie vertical displacement & 15.64 & 14.43 & 15.35 \\
\hline $1^{\text {st }}$ wheelset bending & 49.77 & 38.29 & 46.50 \\
\hline Left rubber resonance & & & 76.68 \\
\hline $2^{\text {nd }}$ wheelset bending & 116.4 & 46.01 & 92.66 \\
\hline $3^{\text {rd }}$ wheelset bending & 143.8 & 74.34 & 112.9 \\
\hline Right rubber resonance & & & 135.1 \\
\hline Left tread bending & & 173.71 & 274.4 \\
\hline Right tread bending & & 173.73 & \\
\hline Wheelset upper block bending & & 191 & \\
\hline Symmetric "umbrella" & 216.6 & & 145.1 \\
\hline Anti-symmetric "umbrella" & 293.7 & 214.52 & 192.2 \\
\hline Resonance of left wheel blocks & & & \\
\hline Resonance of right wheel blocks & & & \\
\hline
\end{tabular}

Table 4. Eigenfrequencies and mode shapes for the wheels compared

Figure 18 and Figure 19 show examples of mode shapes corresponding to the resonance frequencies of rubber elements in the two types of resilient wheels.
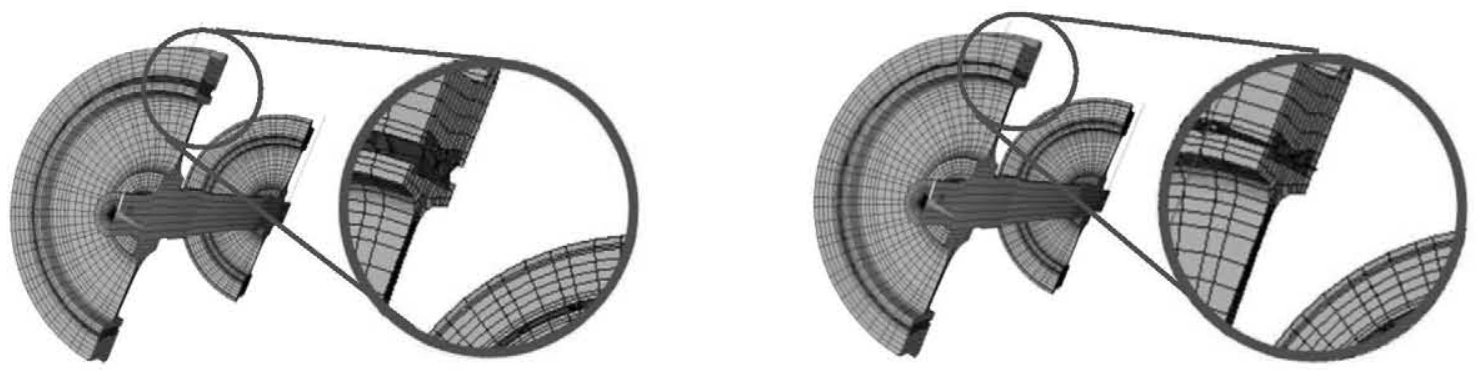

Figure 18. Resilient wheel with rubber blocks. Rubber block resonance on the left wheel $(173.71 \mathrm{~Hz})$
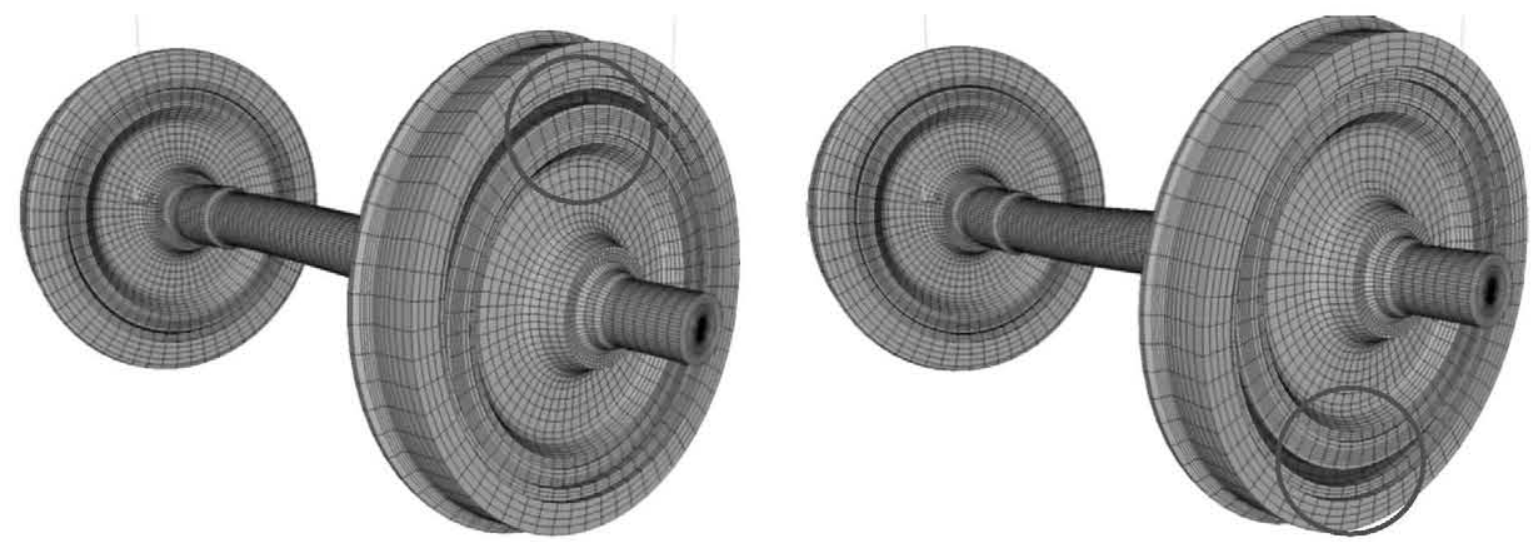

Figure 19. Resilient wheel with V-ring. Ring resonance on the right wheel $(135.1 \mathrm{~Hz})$

As can be seen in Table 4, the first four eigenmodes that appear are the rigid body mode shapes of the carbody and the bogie. The eigenfrequencies at which they occur are practically the same for the three types of wheels. 
The fifth eigenmode ( $1^{\text {st }}$ symmetric wheelset bending) also appears in all the models analysed. The frequency of this mode, however, in the case of the resilient wheel with the V-ring is slightly lower than in the monobloc wheel, as expected, since this wheel has greater elasticity than the monobloc one. In the case of the wheel with rubber blocks, the level is even lower than for the wheel with the rubber ring, because it is also more elastic. It can also be seen that that resonance frequencies for resilient elements in the left and right wheels are different, due to the fact that the model is not completely symmetrical.

For the remaining eigenmodes, there are appreciable differences in the eigenfrequencies and mode shapes. There are resonances in the rubber blocks and in the rubber ring that obviously do not exist in the monobloc wheel. Even so, the first eigenmodes are similar in the three models.

\subsection{Structural vibrations transmitted to the carbody and the bogie}

The following figures show the PSD functions of the speed, $\mathrm{S}_{\mathrm{v}}$, both at the carbody and the bogie's centre of gravity, as well as at the points of connection between the wheelset and the primary suspension springs. In this case, only the vertical component of the vibration has been analysed.

Figure 20 shows the vertical response, $S_{v}$, of the carbody's centre of gravity for the three types of wheels in case A (in phase excitations). This graph clearly shows the eigenfrequency of the carbody, which causes a resonance effect at around $1 \mathrm{~Hz}$, and another one corresponding to the vertical displacement of the bogie, around $15 \mathrm{~Hz}$. It can also be seen that up to around $100 \mathrm{~Hz}$ the behaviour of the three types of wheels is very similar. Beyond $120 \mathrm{~Hz}$ there is a change of trend, and the values corresponding to the resilient wheels are lower than for the monobloc wheel.

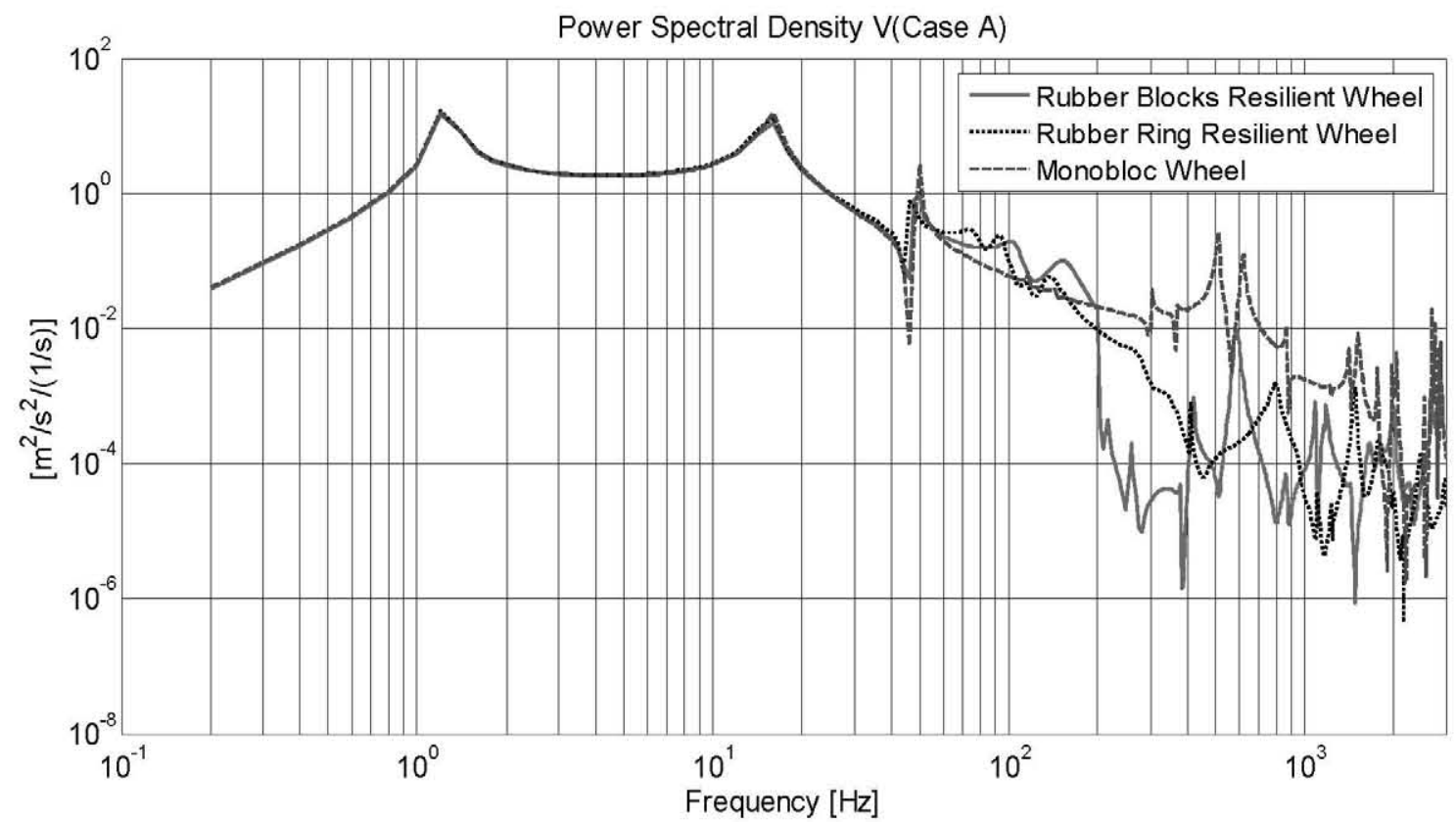

Figure 20: PSD function of vertical speed for the carbody's centre of gravity

Figure 21 shows the vertical response of the bogie's centre of gravity. The natural frequency of the bogie at around $15 \mathrm{~Hz}$ can be seen more clearly here. 


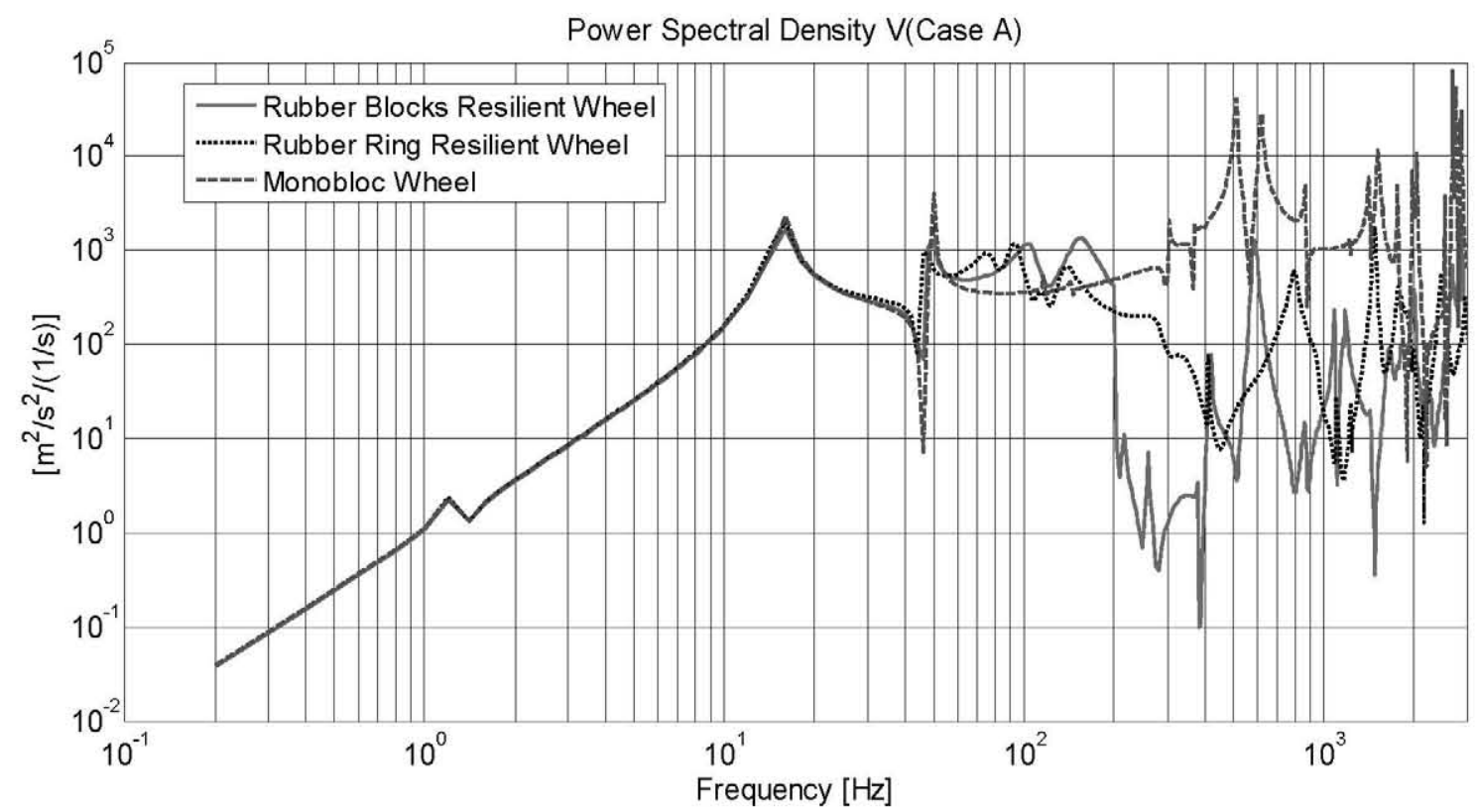

Figure 21. PSD funtion of vertical speed for the bogie's centre of gravity

Although they are not shown here, the PSD functions of the carbody and the bogie in case B (counterphase excitation) are almost zero. This is because the roll rotation is excited in case $B$, and what is represented in these transfer functions is the vertical displacement of the centre of gravity, which is not affected by this rotational motion.

Figure 22 and Figure 23 represent the vertical response at the points of connection between the wheelset and the primary suspension.

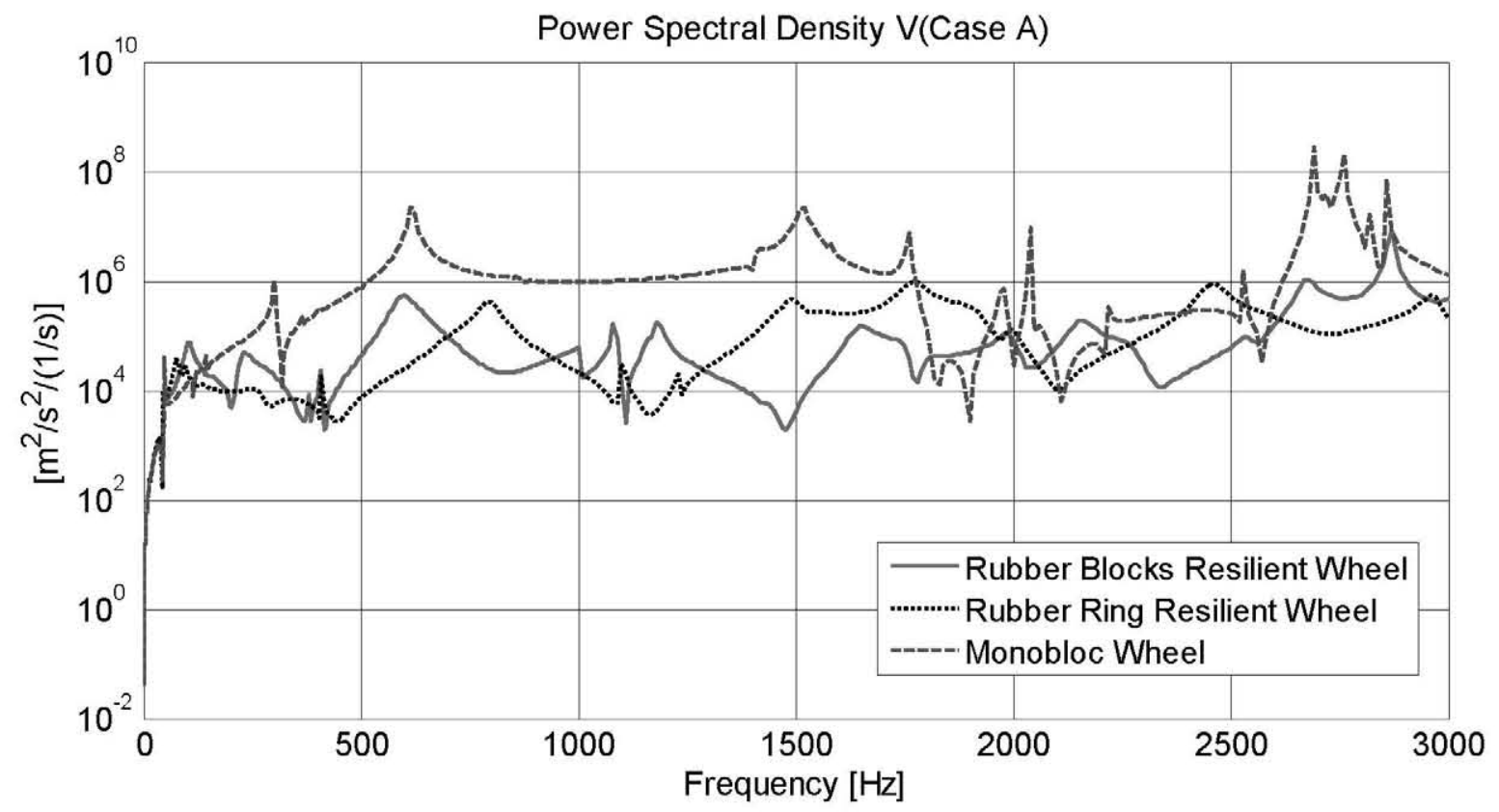

Figure 22. PSD function of vertical speed at the left point of connection with the primary suspension 


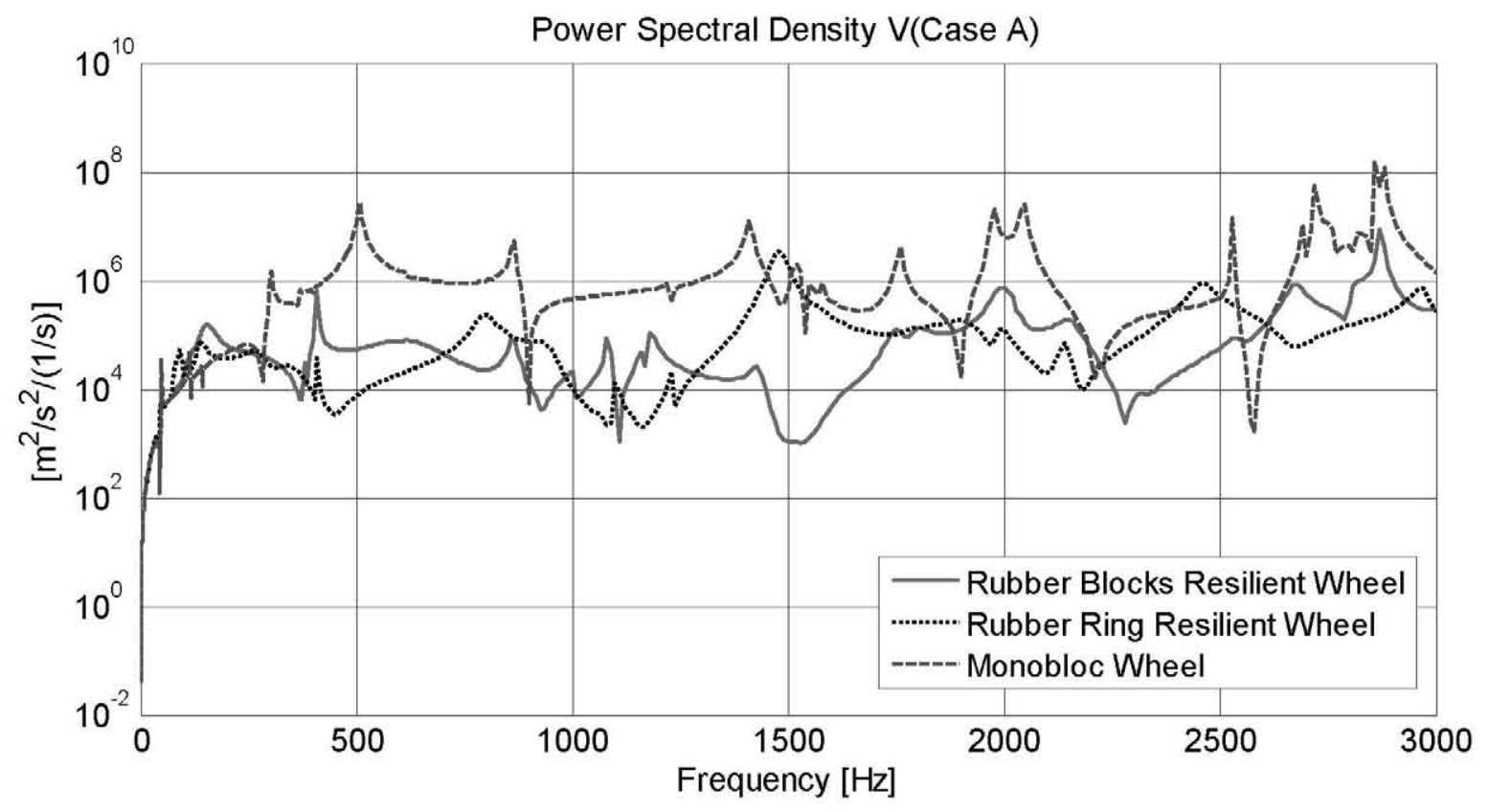

Figure 23. PSD function of vertical speed at the right point of connection with the primary suspension

The results obtained for these points show that, beyond a frequency of around $120 \mathrm{~Hz}$, the vibration energy associated with the vertical movement is much lower for the two resilient wheel models than for the model with the monobloc wheels. Therefore, the vibration energy transmitted to the bogie and the carbody is lower at high frequencies when resilient wheels are used.

It should be remembered that vibration energy, as was seen in section 4.2 , is proportional to the mean square value of the speed, which can be calculated by integrating function $\mathrm{S}_{\mathrm{v}}$. When associating this energy with noise, the speed of those points in the air in contact with the structure is used, whereas the speed of the points on the structure is used for structural vibration assessment. Bearing this in mind, and in order to compare the effectiveness of the resilient wheels in reducing the transmission of structural vibrations to the carbody, PSD functions of the speed of the above-mentioned points have been integrated into the 1 to $3000 \mathrm{~Hz}$ frequency range. This gives us an idea of the amount of energy transmitted to the carbody. The results of the comparison are presented Figure 24.

To facilitate the comparison, the value obtained for the monobloc wheel has been taken as the reference value, the values obtained for the resilient wheels having been divided by this reference value.

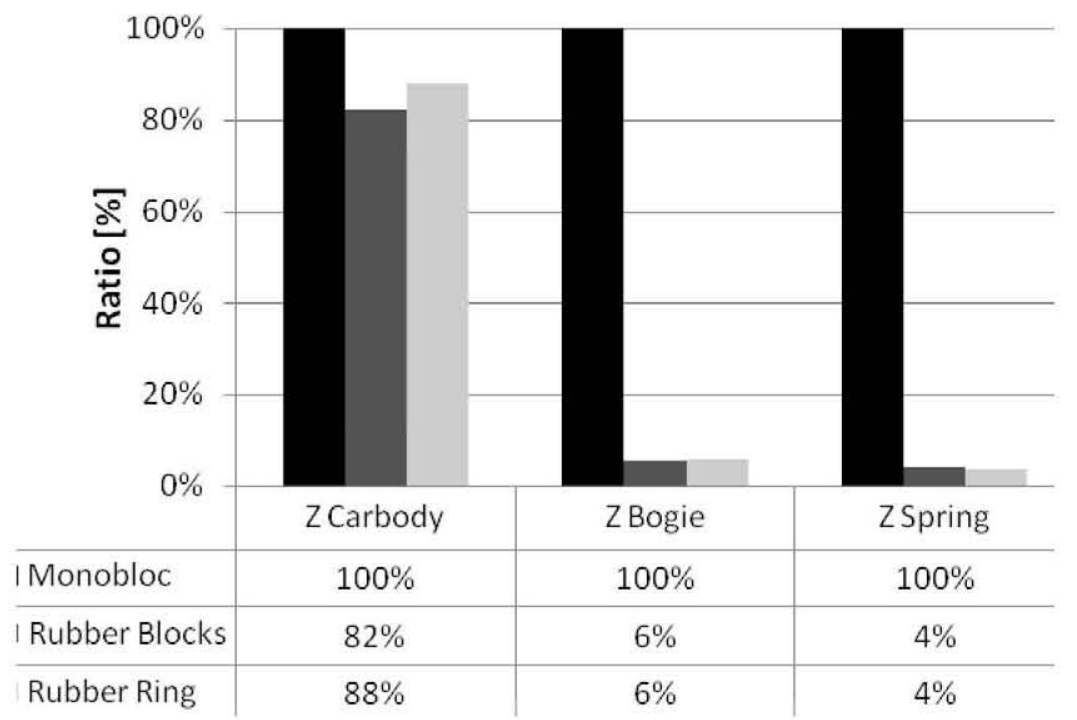

Figure 24. Comparison of the transmission of energy to the carbody, the bogie, and the primary suspension 
As can be seen, the energy transmitted to the points of connection between the wheelset and the primary suspension when using resilient wheels is around $5 \%$ of the energy transmitted when using monobloc wheels, which is equivalent to a $95 \%$ reduction. Something similar occurs with regard to the energy that reaches the bogie. On comparing the energy transmitted to the carbody, however, this difference is not as pronounced, although the resilient wheels still provide a better performance, with reductions of around $20 \%$. This does not mean that, in absolute terms, the vibrations that reach the carbody are greater than those transmitted to other elements located underneath, but that a significant proportion of the vibrations has been filtered by the primary and secondary suspensions, and the difference between using resilient wheels and monobloc wheels is less pronounced than at other points of the vehicle. Although the behaviour of both resilient wheels is very similar, in this case the wheel with rubber blocks is more effective.

\subsection{Structural vibrations transmitted to the track}

To compare the effectiveness in reducing vibrations transmitted to the track, the PSD function of the vertical reaction force has been obtained at the wheel-rail contact points (Figure 25) for the three types of wheels. As in the previous cases, Figure 25 shows that the reaction force for low frequencies (up to $50 \mathrm{~Hz}$ ) is almost the same in all three cases. Between 50 and $120 \mathrm{~Hz}$, the resonance effect due to the rubber elements on the resilient wheels can be detected, and as a result the response of the monobloc wheel is smaller. Beyond $120 \mathrm{~Hz}$, the value corresponding to the two resilient wheels is clearly lower than for the monobloc wheel, except for certain specific frequencies where other resonant effects are observed.

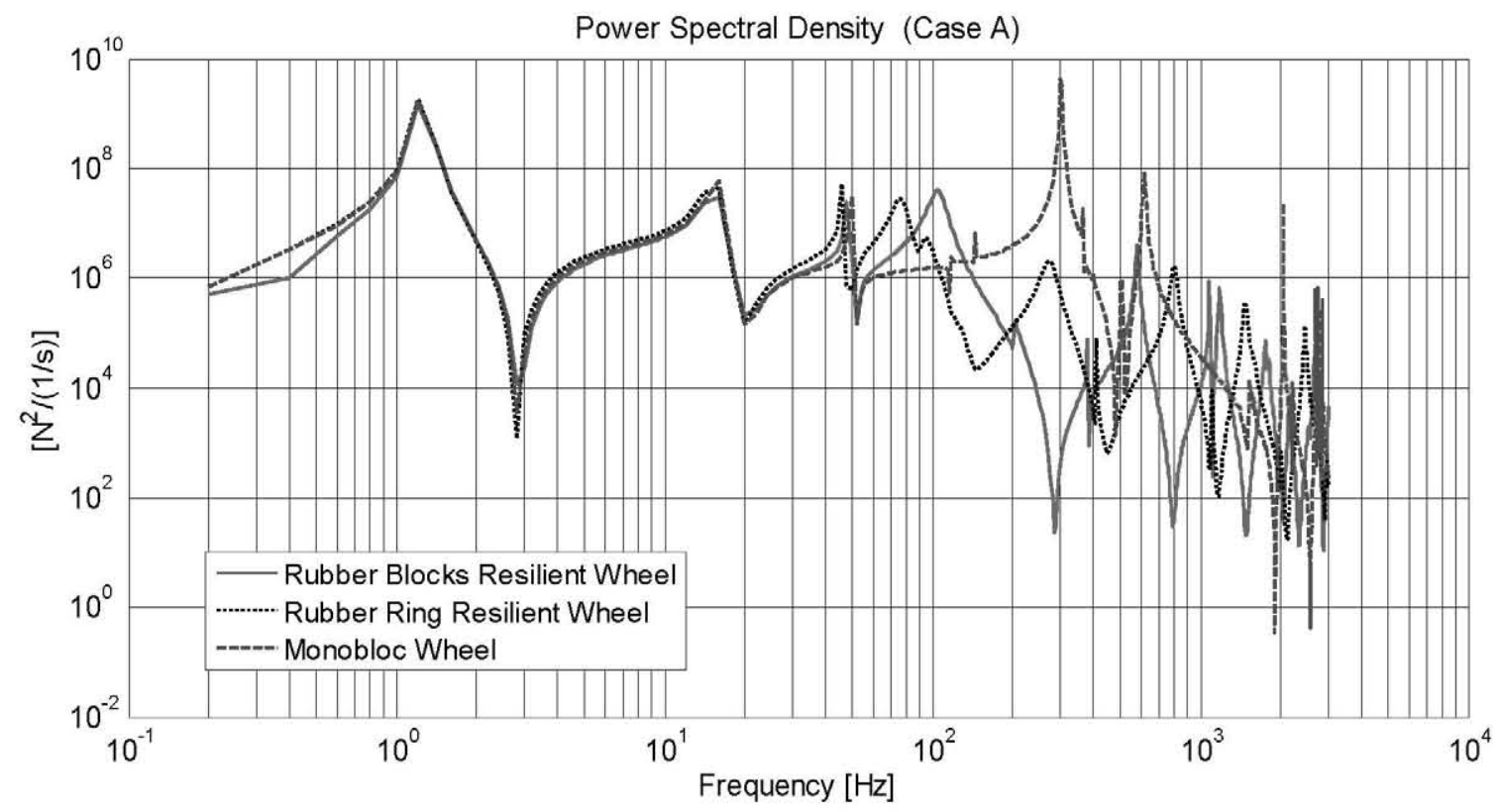

Figure 25: PSD of the vertical reaction force in the left wheel

In order to compare the three types of wheels in terms of reducing the vibrations transmitted to the track, it is possible to estimate the energy transmitted to the track, which, as in the previous cases, will be proportional to the mean square value of the rail's vibration speed. As before, this value can be calculated by integrating the PSD functions of the rail's vibration speed.

As the finite element model used in this study is limited to the vehicle, the displacement of rail points is not known in principle. However, by finding the transfer function, $\mathrm{H}(\omega)$, that relates the force applied to the track to the vertical displacement caused on the track at the load application point, the vibration speed of the rail can be obtained. According to [23], this transfer function module depends on frequency, and can be evaluated according to the following formula: 


$$
|H(\omega)|=\frac{|Z(\omega)|}{|F(\omega)|}=\frac{1}{8 E I\left(\frac{\sqrt{\mid-m \omega^{2^{2}}+c^{2} \omega^{2}}}{4 E I}\right)^{3 / 4}}
$$

$\mathrm{Z}(\omega)$ being the Fourier transform of the vertical displacement of the track at the contact point, $F(\omega)$ being the Fourier transform of the wheel-rail contact force, $\mathrm{k}$ the track stiffness, $\mathrm{c}$ the track damping, $\mathrm{m}$ the track mass, $\mathrm{E}$ its Young modulus, and I its moment of inertia.

As can be deduced from the above formula, the transfer function only depends on the track, and is therefore the same for all the wheels. The values that have been taken for these parameters correspond to the track model data defined in [23].

Once the track transfer function, $\mathrm{H}(\omega)$, is known, the following formula can be established between the PSD functions corresponding to the vertical displacement of the track at the contact point, $\mathrm{S}_{\mathrm{z}}$, and to the contact force, $\mathrm{S}_{\mathrm{F}:}$

$$
|H(\omega)|=\frac{|Z(\omega)|}{|F(\omega)|}=S_{z}(\omega)=|H(\omega)|^{2} \cdot S_{F}(\omega)
$$

As already seen, once the PSD function of the track displacement has been calculated, the corresponding PSD function of the speed can be obtained, simply by applying the formula:

$$
\left|S_{v}(\omega)\right|=\omega^{2} \cdot|H(\omega)|^{2} \cdot S_{F}(\omega)
$$

After calculating the transfer function $|H(\omega)|$ and, on the basis of the latter, the PSD function of the speed, the energy transmitted to the track at the contact point can be estimated, which will be proportional to the integral of $\mathrm{S}_{\mathrm{v}}$.

The results of the comparison between the three wheels are shown in Figure 26. Once again, the monobloc wheel value has been taken as the reference value.

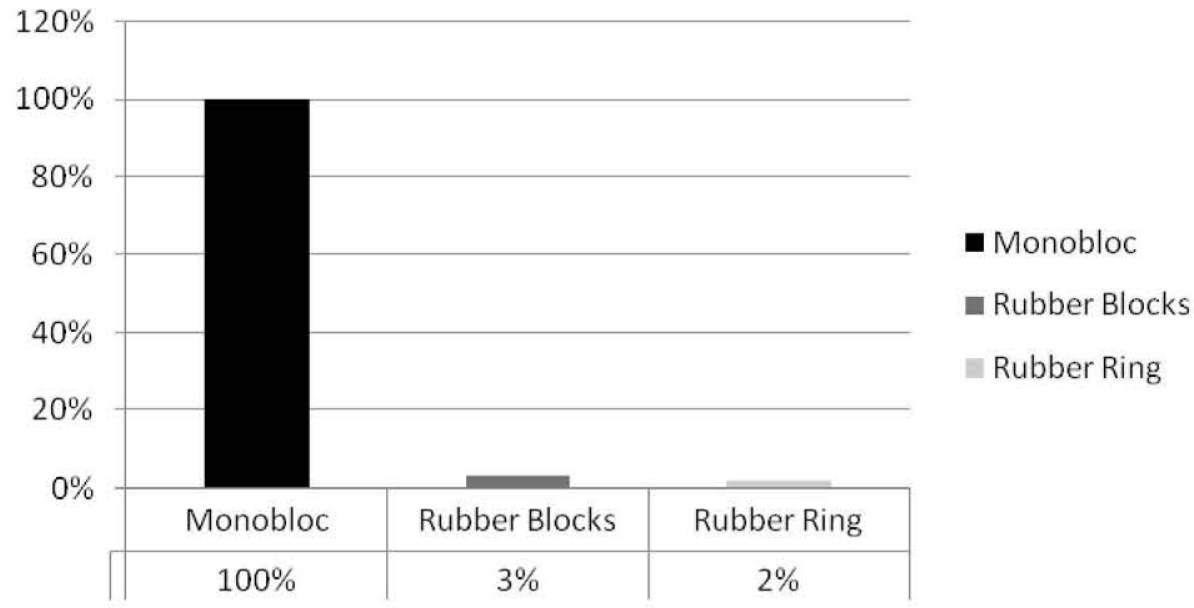

Figure 26. Comparison of the effectiveness of the vibrations transmitted to the track

These results show that the use of resilient wheels considerably reduces the energy transmitted to the track. The difference between the two resilient wheels is very small, although a bigger reduction is achieved with the resilient wheel with a rubber ring.

The value of the energy transmitted to the rail corresponds to the total vibration energy. Part of this energy, mainly at low frequencies, is ground-borne and can reach the structures of adjacent buildings, the vibration of which, in turn, generates noise inside the buildings. 


\subsection{Airborne noise transmission}

As regards direct noise generated by the wheelset, the analysis of noise emitted to the environment has been based on the assumption that the biggest contribution is caused by lateral vibration of the wheel's web and tread.

As indicated in section 4.2, the sound emitted from the wheel has been estimated by dividing its outer lateral surface into a set of rings, a representative node having been chosen for each ring (see Figures 27, 28, 29).

The results of the PSD function of the lateral speed, $\mathrm{S}_{\mathrm{v}}$, which are shown below, correspond to the representative nodes on the above-mentioned annular surfaces. Only the results corresponding to excitation case A are shown. Figure 27 shows the results obtained for the monobloc wheel.

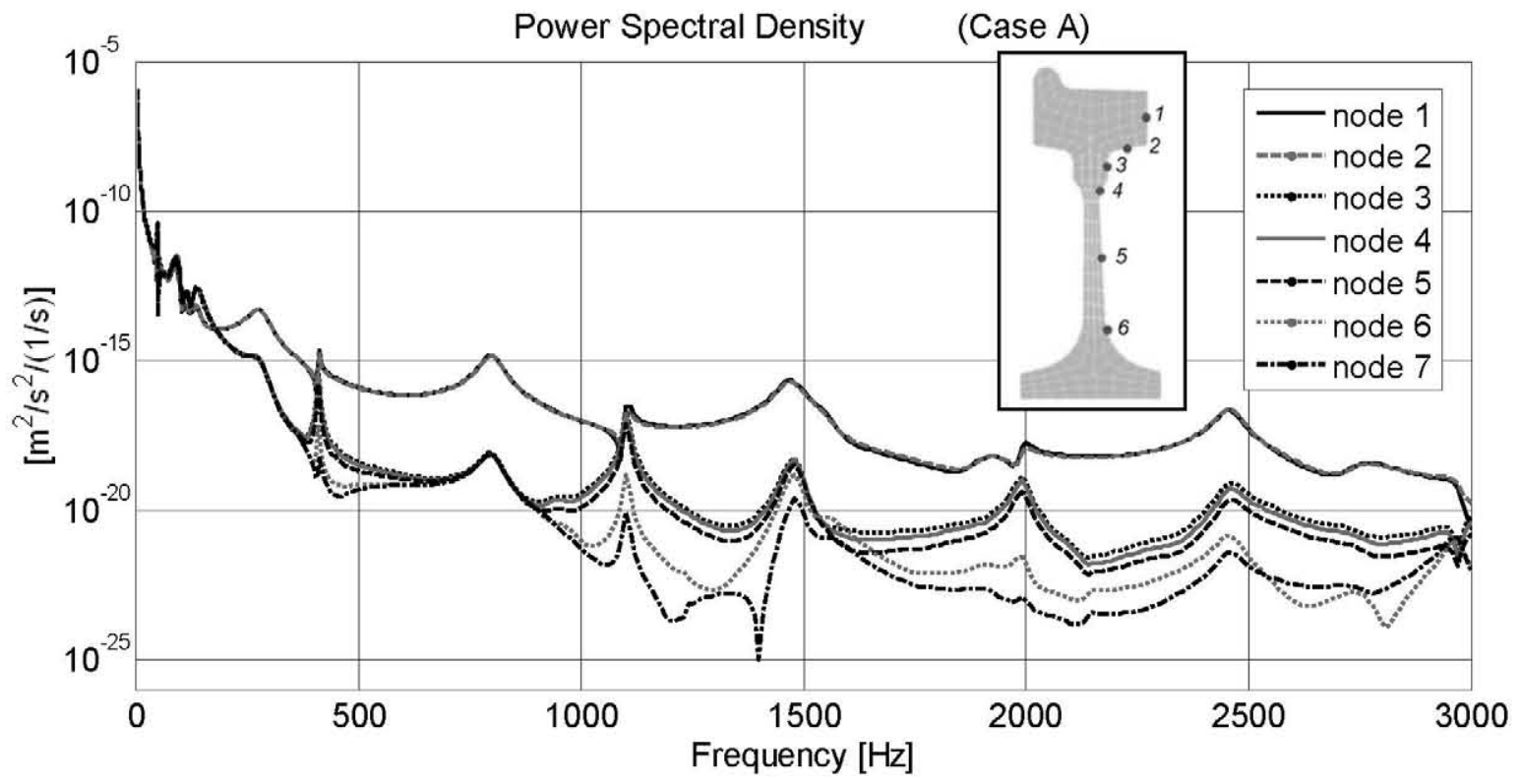

Figure 27. PSD functions of lateral speeds on the monobloc wheel points

Figure 28 shows the results obtained for the resilient wheel with rubber blocks.

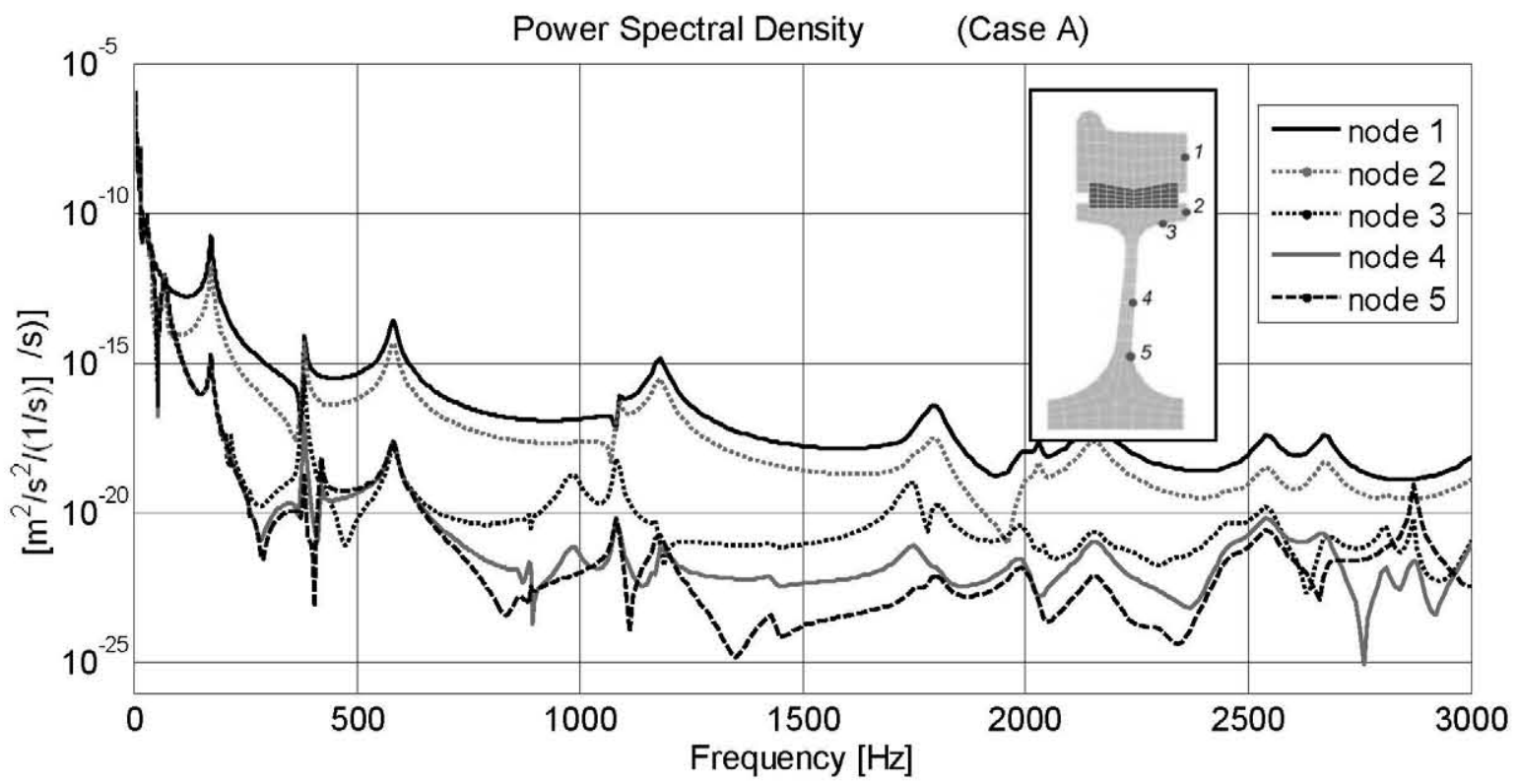

Figure 28. PSD functions of lateral speeds on points of the resilient wheel with rubber blocks

Finally, Figure 29 shows the results obtained for the resilient wheel with a V-shaped rubber ring. 


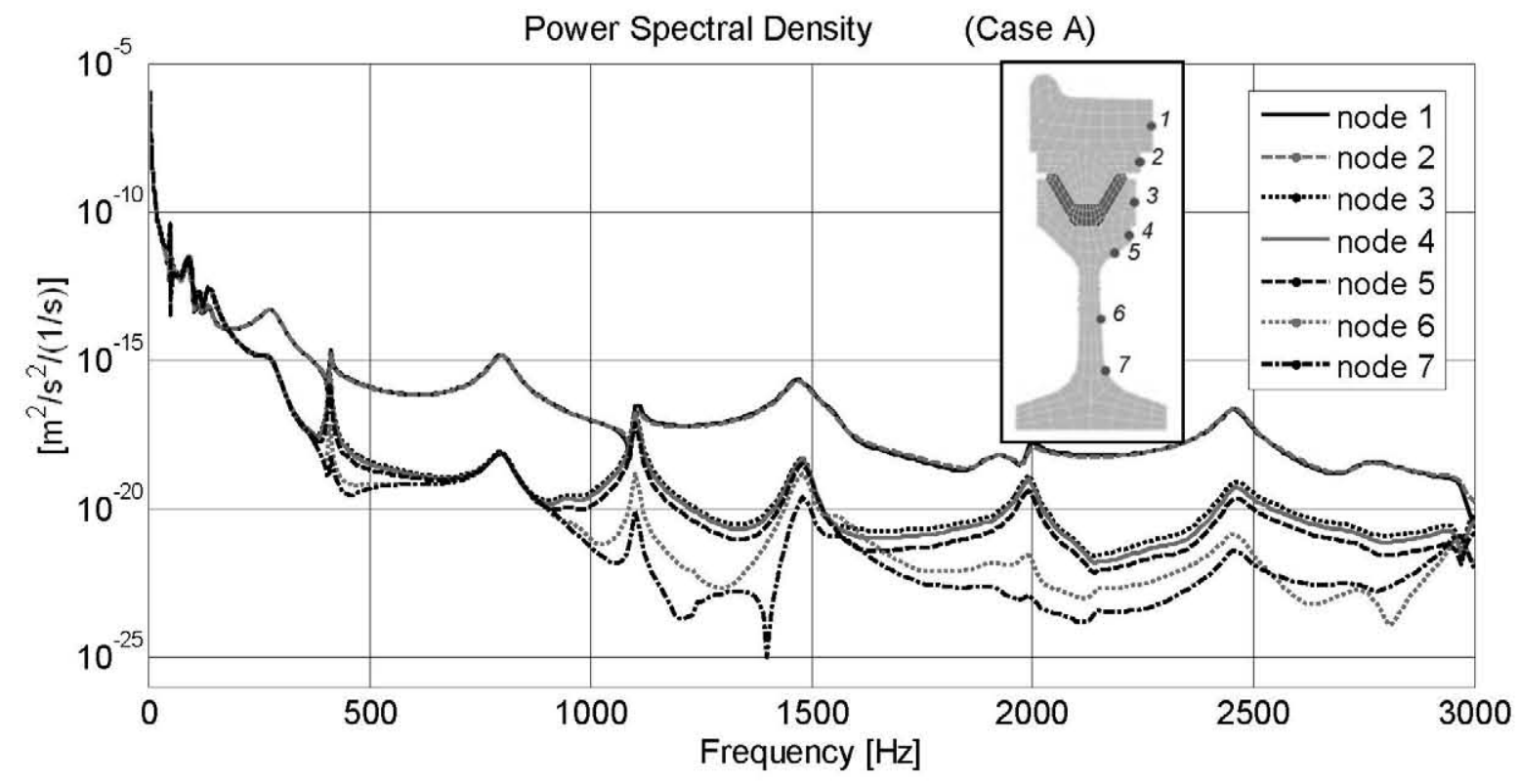

Figure 29. PSD functions of lateral speeds on points of the resilient wheel with a V-shaped rubber ring

On the resilient wheels, the vibration speed of nodes belonging to the annular surfaces defined on the tread (node 1 on the resilient wheel with rubber blocks, and nodes 1 and 2 on the resilient wheel with a V-shaped rubber ring) is clearly higher than that of the other nodes. The speeds of the other nodes gradually decrease as the annular surfaces approach the centre of the wheel.

These results have been used to calculate the sound power emitted, $\mathrm{W}_{\mathrm{T}}$, following the steps indicated in section 4.2. In order to compare the behaviour of the three wheels in terms of noise emission, the entire range of frequencies between 20 and $3000 \mathrm{~Hz}$ has been considered, the lower limit of $20 \mathrm{~Hz}$ being the minimum threshold of human hearing.

The results obtained are shown in Figure 30. Once again, the value obtained for the monobloc wheel has been taken as the reference value (unit value).

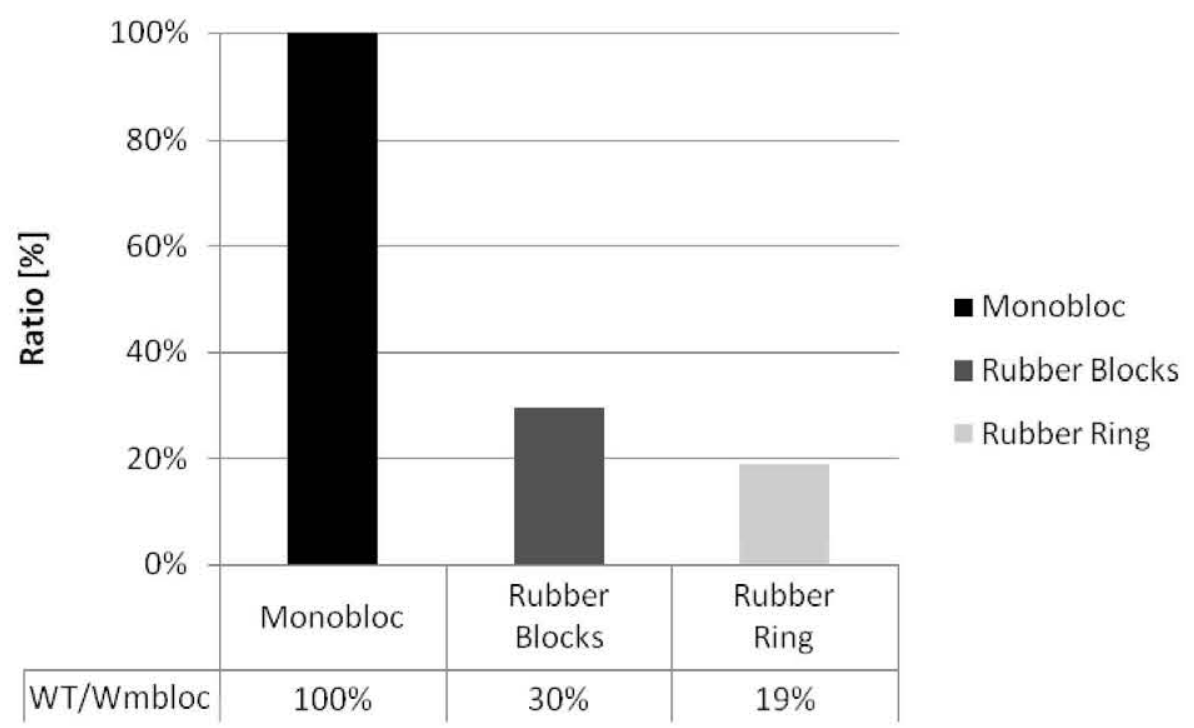

Figure 30. Comparison of airborne noise transmission

It can be seen that the value obtained for the monobloc wheel is clearly higher than the value for the resilient wheels. The results also show that the values obtained for both resilient wheels are very similar, although slightly lower in the case of the resilient wheel with a rubber ring. The latter's behaviour in terms of noise 
emission will, as a result, be slightly better than that for the resilient wheel with rubber blocks. The two resilient wheels do in turn transmit less energy in the form of noise into the environment than the monobloc wheel.

Instead of the sound power emitted by the wheels, which is compared in Figure 30, in order to assess the airborne noise reduction of each resilient wheel in comparison with the monobloc wheel, it is worthy to use the sound power level. By definition, the sound power level, $\mathrm{L}_{\mathrm{W}}$, can be expressed in terms of the sound power, $\mathrm{W}$, as:

$$
L_{W}=10 \cdot \log _{10} \frac{W}{W_{0}}
$$

being $\mathrm{L}_{\mathrm{W}}$ the sound power level, in $\mathrm{dB}, \mathrm{W}$ the sound power, in $\mathrm{W}$, and $\mathrm{W}_{0}$ the $0 \mathrm{~dB}$ reference level, equal to $10^{-12} \mathrm{~W}$.

Bearing in mind this relationship, the difference between the sound power level of two different wheels, 1 and 2 , can be written as:

$$
L_{W 1}-L_{W 2}=10 \cdot\left(\log _{10} \frac{W_{1}}{W_{0}}-\log _{10} \frac{W_{2}}{W_{0}}\right)=10 \cdot \log _{10} \frac{W_{1}}{W_{2}}=10 \cdot \log _{10} r_{12}
$$

where $r_{12}$ is the ratio of the sound powers of wheels 1 and 2 , as can be seen. This equation agrees with the experimental results shown in [26], where a reduction of $3 \mathrm{~dB}$ is obtained between two wheel designs with a ratio of $50 \%$.

Using this expression with the ratios shown in Figure 30, it is found that the noise emission of the rubber resilient wheel with rubber blocks is reduced by $5.2 \mathrm{~dB}$ in comparison with the monobloc wheel. This result agrees with the analytical results reported in [5], with a noise reduction of about $6 \mathrm{~dB}$ between a similar resilient wheel and a monobloc wheel. In the same way, a reduction of $7.2 \mathrm{~dB}$ is found for the resilient wheel with a $\mathrm{V}$-shaped rubber ring. Therefore, the noise emission is $2.0 \mathrm{~dB}$ lower for the resilient wheel with a V-shaped rubber ring than for the resilient wheel with rubber blocks.

\section{$7 \quad$ Concluding remarks}

In this study, the effectiveness of two different types of resilient wheels in reducing noise and vibrations has been compared from three different points of view: structural vibrations transmitted to the carbody and the bogie, structural vibrations transmitted to the track, and noise emissions to the environment.

The finite element method has been used for this purpose with the wheelset having been modelled as an elastic body. By means of this technique, quarter car models have been defined for three different wheels: a monobloc wheel, a resilient wheel with rubber blocks and a resilient wheel with a V-shaped rubber ring. These models have been used to perform both a modal analysis and a spectral analysis, the latter having included an analysis of each wheel's vibratory response under the action of realistic track irregularities. On the basis of this latter calculation, the sound power emitted by the three wheels has also been compared.

In general terms, it has been observed that at low frequencies, below $100 \mathrm{~Hz}$, vibrations at the different points of the vehicle are not reduced by using resilient wheels, which means they are not useful for reducing low-frequency vibrations. This trend, however, is reversed at frequencies of over $100 \mathrm{~Hz}$, and in general terms the use of resilient wheels is advantageous.

As regards the transmission of structural vibrations to the rest of the vehicle, the energy transmitted to the points of connection between the wheelset and the primary suspension when using resilient wheels is around $5 \%$ of the energy transmitted when using monobloc wheels, which represents a reduction of $95 \%$. The same occurs in relation to the energy that reaches the bogie. When comparing the energy transmitted to the carbody, however, this difference is not as pronounced, although the resilient wheels still perform better, with reductions of around $20 \%$. This does not mean, however, that the vibrations transmitted to the carbody are greater in absolute terms than those transmitted to other elements located underneath, but that a significant part of the vibrations has been filtered by the secondary suspension, and the difference between using resilient wheels and monobloc wheels is less pronounced than at other points of the vehicle. Although the behaviour of both resilient wheels is very similar, in this case the wheel with rubber blocks is more effective.

With respect to the transmission of vibrations to the track, the use of resilient wheels significantly reduces the energy transmitted to the track. Although the difference between the two resilient wheels is very small, in this case a greater reduction is obtained with the resilient wheels with a V-ring. 
Finally, with respect to the transmission of noise to the environment, the sound power emitted by the resilient wheels is clearly lower than that emitted by the monobloc wheel. The values obtained for both resilient wheels are also very similar in this case, although the resilient wheel with a V-ring performs slightly better. In particular, the noise emission of the rubber resilient wheel with rubber blocks is reduced by $5.2 \mathrm{~dB}$ in comparison with the monobloc wheel, while a reduction of $7.2 \mathrm{~dB}$ is found for the resilient wheel with a V-shaped rubber ring.

From these results, it can be stated that the two resilient wheels analysed are effective, both for attenuating noise emitted to the environment and for reducing structural vibrations transmitted to the track and the carbody interior.

\section{Acknowledgements}

The authors gratefully thank Metro de Madrid for their cooperation and support throughout this project. Particular thanks go to Mr. Jorge Blanquer (Metro de Madrid), and Mr. Benito Serrano for the contributions made to this project.

\section{REFERENCES}

[1] B. Suarez, B. J. Serrano, P. Rodriguez, J. Blanquer, Comparison of Vibration and Rolling Noise Emission of Resilient and Solid Monobloc Railway Wheels in Underground Lines, Proceedings of the World Congress RR, Montreal, 2006.

[2] B. Suarez, J.A. Chover, P. Rodriguez, J. Blanquer, Comparación de la Emisión de Vibraciones y Ruido de Ruedas Ferroviarias Elásticas y Monobloque en Líneas de Metro, Actas del III Congreso Nacional de Innovación Ferroviaria, Tenerife, 2007.

[3] D. J. Thompson, C. J. C. Jones, A review of the modelling of wheel/rail noise generation, Journal of Sound and Vibration, Vol. 231, pp.519-536, 2000.

[4] D. J. Thompson, C. J. C. Jones, Noise and Vibration from Railway Vehicles, at: Simon Iwnicki (ed.), Handbook of railway vehicle dynamics, CRC Press, ISBN 0849333210, London 2006.

[5] P. Bouvet, N. Vincent, Optimization of Resilient Wheels for Rolling Noise Control, Journal of Sound and Vibration, Vol. 231, pp. 765-777, 2000.

[6] Harris Miller Miller \& Hanson Inc, Transit Noise and Vibration Impact Assessment: Final Report, chapter 7, 1995.

[7] Noise and Vibration, Federal Transit Administration (FTA), U.S. Department of Transportation (DOT).

[8] Wilson, Ihrig \& Associates, Inc., Wheel and Rail Vibration Absorber Testing and Demonstration, TCRP Report 67.

[9] Resilient Wheels. Bochumer-verein [on line] [Accessed 2 April 2008] http://www.bochumerverein.de/englisch/s627.html

[10] Cammell Laird \& Company Ltd, "Improvements in or relating to wheels and axles suitable for use with railway and like vehicles", Patent GB215029, 1923.

[11] Resilient Wheels. Bonatrans [on line] [Accessed 2 April 2008] http://www.bonatrans.cz/en/resilientwheels.html

[12] SAB Wabco, A rail vehicle wheel, Patent EP 489455 B1, 1992.

[13] Krupp Stahl AG, Rail wheel with rubber suspension, Patent DE3328321, 1985.

[14] Patent Products Limited, Wheels having a hub and a metal rim, Patent GB895520, 1962.

[15] E. Sahagian, Reinforced Resilient Wheel, Patent US4765382, 1988.

[16] W. Schiehlen, Elastisches Eisenbahnrad, Patent DE29917935U1, 2000.

[17] Resilient wheels. Lineas de tren [on line] [Accessed 12 July 2005] http://www.revistalineas.com/Lineas28/foro01.htm

[18] H. Claus, W. Schiehlen, Symbolic-Numeric Analysis of Flexible Multibody Systems, Mechanics of Structures and Machines, Vol. 30, Issue 1, pp.1-30, 2002.

[19] H. Claus, W. Schiehlen, System Dynamics of Railcars with Radial- and Lateral elastic wheels, in Lecture Notes in Applied Mechanics 6 (System Dynamics and Long-Term Behaviour of Railway Vehicles, Track and Subgrade), Popp, K. and Schiehlen, W. (eds.), Springer, Berlin, 2003, 65-84.

[20] Sinha Gunjan, The Reinvented Wheel That Killed, Popular Science, Vol. 262, Issue 4, 2003.

[21] G. J. Kuepper, High-Speed Crash Kills 101 , NFPA Journal, November/December 1999

[22] V. Esslinger, R. Kieselbach, R. Koller, B. Weisse, The railway accident of Eschede - technical background, Empa Activities, 2004

[23] C. Esveld, Modern Railway Track, MRT-Productions, ISBN: 90-800324-3-3 
[24] Z. Lu, M. Hecht, Dynamic analysis of a new double deck passenger vehicle with bogie PW200, 4th ADAMS/Rail Users' Conference, Utrecht, 1999.

[25] B. H. Tongue, Principles of Vibration, Oxford University Press, New York, 2002, ISBN: 0-19-514246-2.

[26] G. A. Efthimeros, D. I. Photeinos, Z. G. Diamantis, D. T. Tsahalis, Vibration/noise optimization of a FEM railway wheel model, Engineering Computations, Vol. 19, pp. 922-932, 2002.

[27] W. Thompson, The computation of self-and mutual-radiation impedances for annular and elliptical pistons using Bouwkamp integral, Journal of Sound and Vibration, Vol. 17, pp. 221-233, 1971.

[28] M.R. Lee, R. Singh, Analytical formulations for annular disk sound radiation using structural modes, Journal of the Acoustical Society of America, Vol. 95, pp. 3311-3323, 1994.

[29] W.P. Rdzanek Jr., Z. Engel, Asymptotic formula for the acoustic power output of a clamped annular plate, Applied Acoustics, Vol. 60, pp. 29-43, 2000.

[30] H. Lee, R. Singh, Acoustic radiation from out-of-plane modes of an annular disk using thin and thick plate theories, Journal of Sound and Vibration, Vol. 282, pp.313-339, 2005.

[31] H. Lee, R. Singh, Self and mutual radiation from flexural and radial modes of a thick annular disk, Journal of Sound and Vibration, Vol. 286, pp. 1032-1040, 2005.

[32] H. Lee, R. Singh, Comparison of two analytical methods used to calculate sound radiation from radial vibration modes of a thick annular disk, Journal of Sound and Vibration, Vol. 285, pp. 1210-1216, 2005.

[33] Rossing (Ed.), Springer Handbook of Acoustics, Springer, 2007, New York, ISBN 978-0-387-30446-5.

[34] B. R. Davis and A. G. Thompson, Power Spectral Density of Road Profiles, Vehicle System Dynamics, Vol. 35 , pp. 409-415, 2001.

[35] N. Vincent, J.R. Koch, H. Chollet and J.Y. Guerder, Curve squeal of urban rolling stock-Part 1: State of the art and field measurements, Journal of Sound and Vibration, Vol. 293, pp. 691-700, 2006.

[36] M. Melis and F. J. González, Ferrocarriles metropolitanos : tranvias, metros ligeros y metros convencionales, Colegio de Ingenieros de Caminos, Canales y Puertos, 2004, Madrid. ISBN 8438002870.

[37] C. J. C. Jones and D. J. Thompson, Rolling noise generated by railway wheels with visco-elastic layers, Journal of Sound and Vibration, Vol. 231, 779-790. 